\title{
Production of Negative-Emissions Steel Using a Reducing Gas Derived from DFB Gasification
}

\author{
Sébastien Pissot ${ }^{1, * \mathbb{D}}$, Henrik Thunman ${ }^{1}$, Peter Samuelsson ${ }^{2} \mathbb{D}$ and Martin Seemann ${ }^{1}$ \\ 1 Department of Space, Earth, and Environment, Division of Energy Technology, \\ Chalmers University of Technology, 41296 Göteborg, Sweden; henrik.thunman@chalmers.se (H.T.); \\ martin.seemann@chalmers.se (M.S.) \\ 2 Department of Materials Science and Engineering, KTH Royal Institute of Technology, \\ 10044 Stockholm, Sweden; petersam@kth.se \\ * Correspondence: pissot@chalmers.se
}

Citation: Pissot, S.; Thunman, H.; Samuelsson, P.; Seemann, M. Production of Negative-Emissions Steel Using a Reducing Gas Derived from DFB Gasification. Energies 2021, 14, 4835. https://doi.org/10.3390/ en14164835

Academic Editor: Dalia Štreimikienè

Received: 30 June 2021

Accepted: 5 August 2021

Published: 8 August 2021

Publisher's Note: MDPI stays neutral with regard to jurisdictional claims in published maps and institutional affiliations.

Copyright: (C) 2021 by the authors. Licensee MDPI, Basel, Switzerland. This article is an open access article distributed under the terms and conditions of the Creative Commons Attribution (CC BY) license (https:// creativecommons.org/licenses/by/ $4.0 /)$
Abstract: A dual fluidized bed (DFB) gasification process is proposed to produce sustainable reducing gas for the direct reduction (DR) of iron ore. This novel steelmaking route is compared with the established process for DR, which is based on natural gas, and with the emerging DR technology using electrolysis-generated hydrogen as the reducing gas. The DFB-DR route is found to produce reducing gas that meets the requirement of the DR reactor, based on existing MIDREX plants, and which is produced with an energetic efficiency comparable with the natural gas route. The DFB-DR path is the only route considered that allows negative $\mathrm{CO}_{2}$ emissions, enabling a $145 \%$ decrease in emissions relative to the traditional blast furnace-basic oxygen furnace (BF-BOF) route. A reducing gas cost between 45-60 EUR/MWh is obtained, which makes it competitive with the hydrogen route, but not the natural gas route. The cost estimation for liquid steel production shows that, in Sweden, the DFB-DR route cannot compete with the natural gas and BF-BOF routes without a cost associated with carbon emissions and a revenue attributed to negative emissions. When the cost and revenue are set as equal, the DFB-DR route becomes the most competitive for a carbon price $>60 \mathrm{EUR} / \mathrm{tCO}_{2}$.

Keywords: gasification; DFB; DRI; iron reduction; steelmaking; negative emissions; chemical-looping gasification; biomass

\section{Introduction}

The iron and steel industry accounts for $4-7 \%$ of global $\mathrm{CO}_{2}$ emissions, making it one of the largest industrial emitters [1]. The emissions intensity of the steelmaking industry is due to the use of fossil fuels, mainly coal and coke, to provide the energy required by the process as well as a reducing agent. Since the 1970s, direct reduction (DR) processes, which rely on natural gas rather than coal or coke, have emerged and gained traction. In DR processes, iron ore in the form of lumps, pellets, or fine powder is reduced in the solid state to direct reduced iron (DRI), which is thereafter converted to steel in an electric arc furnace (EAF). The most widely used DR process, MIDREX, has a $\mathrm{CO}_{2}$ intensity that is $30-45 \%$ that of the traditional blast furnace-basic oxygen furnace (BF-BOF) route when using natural gas [2]. However, $\mathrm{CO}_{2}$ emissions remain high at 1.1-1.2 $\mathrm{tCO}_{2}$ per tonne of steel. The use of scrap significantly reduces the energy consumption of the process, although scrap input into the EAF is limited by its availability. To reduce or completely abate emissions from steelmaking, carbon capture and storage (CCS) must be employed or fossil fuels must be replaced by renewable sources. Hydrogen, produced from water electrolysis using fossil-free electricity, is an alternative to natural gas that has been proposed for the DRI-EAF route, as it can reduce iron ore to metal iron. Furthermore, in combination with electricity, hydrogen can cover the energy demand of the process. The HYBRIT project in Sweden aims to demonstrate the viability of such a process [3]. The first pilot plant to test the production of DRI using hydrogen was started in 2020. 
Meeting the 1.5 or $2.0^{\circ} \mathrm{C}$ targets put forward by the IPCC [4] will likely require the achievement of negative emissions of $\mathrm{CO}_{2}$ [5]. This means that the use of biomass coupled with CCS should be considered for all plants in which fossil resources are currently being used, in particular in applications that require a carbon input, as biomass and captured $\mathrm{CO}_{2}$ are the only renewable carbon sources. In steelmaking, biomass can act simultaneously as the reducing agent for the iron ore, the carbon source for the required carbon content of the steel, and the energy source. In the DRI-EAF route, the reduction agent can be produced through steam gasification of biomass to produce a gas that is rich in $\mathrm{H}_{2}$ and $\mathrm{CO}$. The only biomass steam gasification technology that has been demonstrated at industrial-scale is the dual fluidized bed (DFB) gasification technology [6].

A DFB gasification system consists of two interconnected reactors, a gasification reactor in which the biomass is converted to a gas, referred to as the 'raw gas', and a combustor in which the unconverted biochar from the gasifier is burnt, thereby providing heat to the process [7]. The heat and char are transported between the reactors by a fluidized bed. The integration of DFB gasification with the BF-BOF route has recently been investigated by Rosenfeld et al. [8] and Müller et al. [9]. In both of these works, $\mathrm{H}_{2}$ from biomass gasification and the electrolysis of water is used to methanize the $\mathrm{CO}_{2}$ produced from the steel mill, thereby reducing both the emissions and the need for natural gas for heating purposes [8,9]. The proposed DFB gasification configuration is the sorptionenhanced reforming (SER) technology, which relies on the adsorption of $\mathrm{CO}_{2}$ in the gasifier and its release in the combustor to produce a $\mathrm{H}_{2}$-rich syngas [10]. When the combustor is fired with pure oxygen, a concentrated $\mathrm{CO}_{2}$-stream is formed, which can be converted to methane to replace the natural gas used in the steel mill.

The integration of DFB gasification with DR of iron has recently been investigated by Hammerschmid et al. [11] as a means to provide a biogenic-based reducing gas for a DR steelmaking process. Here again, the SER technology has been proposed, as well as its Oxyfuel version, which can provide net-negative emissions. The authors found that the reducing gas was suitable for use in DR. The cost of the reducing gas was found to be comparable to the cost of steam-reformed natural gas in Europe, albeit about twice as expensive as the reducing agent used in the $\mathrm{BF}-\mathrm{BOF}$ route. The net-negative-emissions gas was found to be in the range of the steam-reformed natural gas only if the Oxyfuel-SER unit was integrated into the DRI-EAF plant, taking advantage of the existing air separation unit (ASU) to produce pure oxygen, and if the $\mathrm{CO}_{2}$ was utilized. Otherwise, the SER unit without oxyfuel combustion is preferable. Even without $\mathrm{CO}_{2}$ utilization, the biomass-based reducing gas leads to a decrease in emissions of more than $80 \%$ compared to the BF-BOF route. Hammerschmid and colleagues estimated that about 3.5 Mt of crude steel could be produced in this way in Austria, which would represent a 50\% decrease in emissions from the Austrian iron and steel sector [11].

In similarity to the study of Hammerschmid et al. [11], the present work aims to describe the feasibility of using DFB gasification to provide a renewable reducing gas to a DRI-EAF process. However, the process that we propose here is not based on the SER technology but involves instead the use of slag from steelmaking as the bed material, which can act as an oxygen carrier, thereby enabling inherent $\mathrm{CO}_{2}$ separation in the DFB gasification process. The production of steel using a reducing gas generated during DFB gasification is compared with the traditional DR route using natural gas, as well as with the use of hydrogen from electrolysis for steel production. Based on the mass and energy balances, the energy efficiency of the three DR routes is compared. As the DR reactor has flexibility with respect to a wide range of reducing gas characteristics, the economic benefit of one DR route over another ultimately comes down to the cost of the reducing gas that they can produce; this cost is, therefore, compared in this work. The economics of the DFB gasification route is assessed based on economic data obtained from the GoBiGas plant [12], which is the largest DFB gasification plant to date, so as to estimate the costs related to the DFB gasification section. In contrast to Hammerschmid et al. [11], the DR reactor is included in the mass and heat balances of the system, and the specificities of its 
operation with a DFB gasification-derived gas are discussed. The total production cost of the liquid steel is also assessed for the three routes and compared with the traditional $\mathrm{BF}-\mathrm{BOF}$ route, accounting for the economic consequences of positive and negative $\mathrm{CO}_{2}$ emissions, respectively.

\section{Descriptions of the DRI-EAF Steelmaking Route and of the Compared DR Routes}

\subsection{DRI-EAF Route}

The most commonly used process for DR of iron ore, the MIDREX process, is based on a shaft furnace into which iron ore is introduced as lumps or pellets. The ore is reduced by a syngas, a mixture of $\mathrm{H}_{2}$ and $\mathrm{CO}$, which is typically produced by reforming natural gas with steam and $\mathrm{CO}_{2}$. The heat demand of the DR reactor is covered fully by the sensible heat content of the reducing gas introduced, which is typically at temperatures $>900{ }^{\circ} \mathrm{C}$. The iron ore is introduced at the top of the furnace and is preheated by the top-gas, which exits the furnace at a temperature that is typically $350{ }^{\circ} \mathrm{C}$. The ore then enters the reaction zone, where it is reduced by $\mathrm{H}_{2}$ and $\mathrm{CO}$ to metallic iron, although some $\mathrm{FeO}$ usually remains. Thereafter, the reduced iron cools down in the transition zone, where it encounters the natural gas that is injected at the bottom of the furnace to increase the carbon content of the DRI via the carburization reaction [13]. As the carburization reaction with methane is endothermic, it further cools the DRI. To address this issue, MIDREX Research and Technology Development has developed a way to add CO from the reforming of the natural gas to the transition zone, which results in exothermic carburization of the DRI [13]. The hot DRI is extracted from the bottom of the reactor. From there, it can be cooled before storage or transportation as DRI. It can also be compacted at high temperature; it is then referred to as hot-briquetted iron, which is stored or transported. Alternatively, the DRI can be charged hot directly into the EAF to reduce the energy consumption of that step [14].

The carburization of $\mathrm{Fe}$ to $\mathrm{Fe}_{3} \mathrm{C}$ can occur with hydrocarbons following reaction R1 (described for a hydrocarbon with $\mathrm{H} / \mathrm{C}$ ratio $\mathrm{y}$ ) or with $\mathrm{CO}$ following reactions $\mathrm{R} 2$ and $\mathrm{R} 3$. For the main light hydrocarbons found in biomass gasification gas, methane, ethylene, and propylene, the heats of reaction following $\mathrm{R} 1$ are $27,-7$, and $0 \mathrm{~kJ} / \mathrm{mol} \mathrm{Fe}$, respectively. The heat of reactions for $\mathrm{R} 2$ and $\mathrm{R} 3$ are -56 and $-42 \mathrm{~kJ} / \mathrm{mol} \mathrm{Fe}$, respectively.

$$
\begin{gathered}
\mathrm{Fe}+\frac{1}{3} \mathrm{CH}_{y} \rightarrow \frac{1}{3} \mathrm{Fe}_{3} \mathrm{C}+\frac{y}{6} \mathrm{H}_{2} \\
\mathrm{Fe}+\frac{2}{3} \mathrm{CO} \rightarrow \frac{1}{3} \mathrm{Fe}_{3} \mathrm{C}+\frac{1}{3} \mathrm{CO}_{2} \\
\mathrm{Fe}+\frac{1}{3} \mathrm{CO}+\frac{1}{3} \mathrm{H}_{2} \rightarrow \frac{1}{3} \mathrm{Fe}_{3} \mathrm{C}+\frac{1}{3} \mathrm{H}_{2} \mathrm{O}
\end{gathered}
$$

The target for the carbon content of the DRI depends on several factors. First, the carbon content of the steel will reflect the end-use applications. Carbon in the DRI is also desirable to decrease the risk of re-oxidation of the iron when in contact with air [15]. In the EAF, several considerations favor a relatively high carbon content. In the EAF bath, carbon reacts with the remaining FeO in the liquid metal, thereby improving the foaming of the slag, which in turns protects the refractory from the electrical arcs [16]. The presence of carbon in the DRI also contributes to the removal of nitrogen from the steel, which is a major challenge in steelmaking, and reduces the overall energy consumption of the EAF process [17].

In the iron ore that is introduced into the DR process, minerals other than iron are found. These typically contain silicon and aluminum oxides and are collectively referred to as gangue. In the EAF, this fraction is extracted from the molten iron by the addition of fluxing agents, typically calcined lime and limestone [18]. Thus, a slag is formed, the bulk oxide composition of which is typically $\mathrm{CaO}, \mathrm{FeO}, \mathrm{SiO}_{2}, \mathrm{MgO}, \mathrm{Al}_{2} \mathrm{O}_{3}$, and $\mathrm{MnO}$ [19]. Although the composition of the slag depends on the steelmaking process and fluxing agents used, the bulk compositions of the EAF and BOF slags are similar; notably, they have relatively high iron contents (e.g., 20-30\% in mass for EAF slag) [19]. 


\subsection{DFB Gasification}

In line with the demands of the DR process and the aim of producing a negativeemissions steel, the goals of the biomass gasification step are two-fold, in that it must (1) provide the reduction and carburization gases to the DR process and (2) facilitate the separation of $\mathrm{CO}_{2}$ for sequestration. Regarding the second goal, the separation of heat production and gasification in DFB gasification systems allows for flexibility in how the carbon is distributed between the outputs of the two reactors, i.e., the flue gas from the combustor and the raw gas from the gasifier. The DFB gasification system can notably be operated in configurations that facilitate the separation of $\mathrm{CO}_{2}$. Some of the configurations in which the DFB gasification system can be operated are: (1) the use of pure oxygen as oxidant in the combustor to produce a $\mathrm{CO}_{2}$-rich flue gas, (2) the addition of electric heating elements in the loop to provide heat to the process, and (3) the use of bed materials that react with the oxygen from the air in the combustor, thereby releasing heat in quantities that are comparable to those released during the combustion of fuel [20]. The last two configurations allow, in theory, for the complete conversion of the fuel in the gasifier, which concentrates all the carbon in the raw gas. In these two configurations, $\mathrm{CO}_{2}$ separation is facilitated, as compared with the regular DFB configuration (based on the combustion of char with air), since the concentration of $\mathrm{CO}_{2}$ is higher in the raw gas than in the nitrogen-diluted flue gas.

Materials that have the capability to bind oxygen from air and release it under morereducing conditions, such as those produced by fuel decomposition, are called oxygen carriers, and they are typically rich in transition metals. The phenomenon of oxygen binding and these materials are the basis for the chemical-looping combustion (CLC) technology [21-23]. In CLC, an oxygen carrier bed material is oxidized with air in a so-called air reactor and reduced in a fuel reactor with a gaseous or solid fuel, thereby producing a $\mathrm{CO}_{2}$ stream that is undiluted with nitrogen, as depicted in the left-hand panel of Figure 1. The capability of an oxygen carrier to release oxygen is also used as a means to increase fuel burnout in fluidized bed boilers, in a technology referred to as oxygen carrier-aided combustion (OCAC) [24].

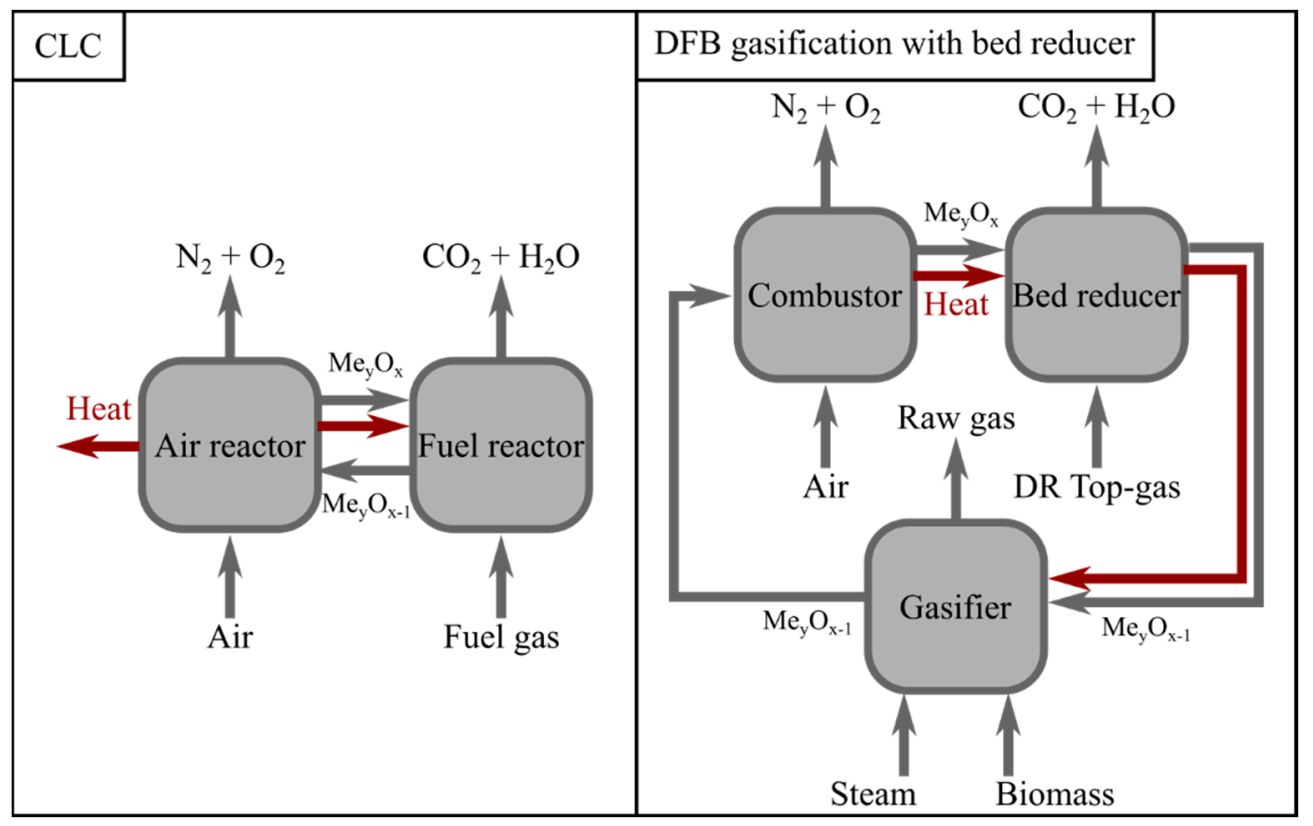

Figure 1. Schematic of the gas chemical-looping combustion technology (left-hand panel) and of the DFB gasification loop in the proposed process (right-hand panel), where a bed reducer section is introduced. $\mathrm{Me}_{\mathrm{y}} \mathrm{O}_{\mathrm{x}}$ refers to the oxidized oxygen-carrying bed material, with Me referring to metal, and $\mathrm{Me}_{\mathrm{y}} \mathrm{O}_{\mathrm{x}-1}$ is the reduced form of the oxygen carrier. 
In an effort to identify cost-efficient oxygen carriers for chemical-looping and OCAC technologies and to increase their circularity, BOF slag, which is an abundant byproduct of the steelmaking industry, has recently been investigated as an oxygen carrier [25-27]. Given their composition similarities, EAF slag and BOF slag most likely have similar oxygen-carrying propensities. This means that the slag from the DRI-EAF process could be used as the bed material in the DFB gasification section of the process. This would also increase the circularity of the process, since a byproduct is used as a crucial component of the process.

The oxidation of the slag in the combustor results in the transport of oxygen to the gasifier, where it will be released by reacting with the raw gas species. $\mathrm{H}_{2}$ and $\mathrm{CO}$ will be the species that are most likely to be oxidized, due to their reactivities and high concentrations in the gas. Consequently, the introduction of oxygen into the gasifier decreases the reducing gas yield. Transport of oxygen to the gasifier must, therefore, be avoided. This can be achieved by introducing a reducing gas in a fluidized bed section between the combustor and gasifier, referred to as the bed reducer in this work. A portion of the top-gas from the DR step, which contains $\mathrm{H}_{2}$ and $\mathrm{CO}$, can be used for this purpose. The DFB gasification loop in this case is essentially a CLC loop, where the combustor is the air reactor, the bed reducer is the fuel reactor, and the gasifier is a third reactor that is introduced into the loop, as shown in the right-hand panel of Figure 1. The heat is circulated by the slag material from the combustor to the gasifier, passing through the bed reducer, where the bed is reduced. The heat of the DFB process is, therefore, provided by the combustion of part of the DR top-gas.

In this configuration, the combustion of char in the combustor is unnecessary, and even undesirable, since it results in the release of $\mathrm{CO}_{2}$ in the flue gas. This represents a loss of negative emissions. Alternatively, this requires an energy-intensive separation because the $\mathrm{CO}_{2}$ in the flue gas is at low concentration, which decreases the plant efficiency. Nonetheless, combustion of some carbon-containing species in the combustor is acceptable, especially for those species that are not valorized and cannot be handled in a proper way. These species include the tar and soot produced during decomposition of the fuel. Carbon coking the bed material is also oxidized in the combustor, resulting in the regeneration of catalytic sites. As the transport of char to the combustor is no longer desirable when slag is used as the bed material, the char must be removed from the circulating bed material, and this can be achieved using a carbon stripper [28]. The char can then be valorized, for instance in the EAF step, where it can replace the coke and other carbonaceous products that are typically used. Alternatively, it can be sold.

\subsection{Comparison Cases}

In this work, the DR of iron using DFB gasification gas, referred to as DFB-DR, is compared with the traditional DR of iron using natural gas, NG-DR, and with the DR of iron using hydrogen produced through the electrolysis of water, $\mathrm{H}_{2}$-DR. These cases are schematically depicted in Figure 2. All three cases are based on the MIDREX DR shaft furnace, with the top-gas exiting at a temperature of $350{ }^{\circ} \mathrm{C}$.

For the NG-DR case, as mentioned above, the reducing gas is produced through reforming natural gas. The reformer is operated at high temperature, typically $980{ }^{\circ} \mathrm{C}$, so the reducing gas is at the temperature required for the reduction. Still, some small amount of oxygen can be added to compensate for heat losses and to reach the desired temperature. Part of the top-gas is introduced into the reformer, where it provides the $\mathrm{H}_{2} \mathrm{O}$ and $\mathrm{CO}_{2}$ needed for reforming, and the remainder is burnt to cover the reformer heat demand.

In the $\mathrm{H}_{2}$-DR case, the reducing gas, which is produced from electrolysis, contains only $\mathrm{H}_{2}$ as the reductant. The reducing gas is preheated using the heat from the top-gas, although about $10 \%$ of the $\mathrm{H}_{2}$ needs to be burnt with pure oxygen (byproduct of the electrolysis) to reach the temperature required for the DR reactor, as indicated by the dashed line in the middle panel of Figure 2. This temperature is assumed to be $1000{ }^{\circ} \mathrm{C}$, which is also the temperature targeted for the DFB-DR case, so as to be close to the temperature exiting the 
steam reformer in the NG-DR case. All of the hydrogen in the top-gas in the $\mathrm{H}_{2}$-DR case is recirculated to the reducing gas. Ignoring unavoidable losses, the water extracted from the top-gas exactly covers the water demand of the electrolyzer. It is important to note that the DRI is not carburized in the $\mathrm{H}_{2}$-DR case, leading to different behavior in the EAF step and a greater need for input of char or coke when melting the DRI.

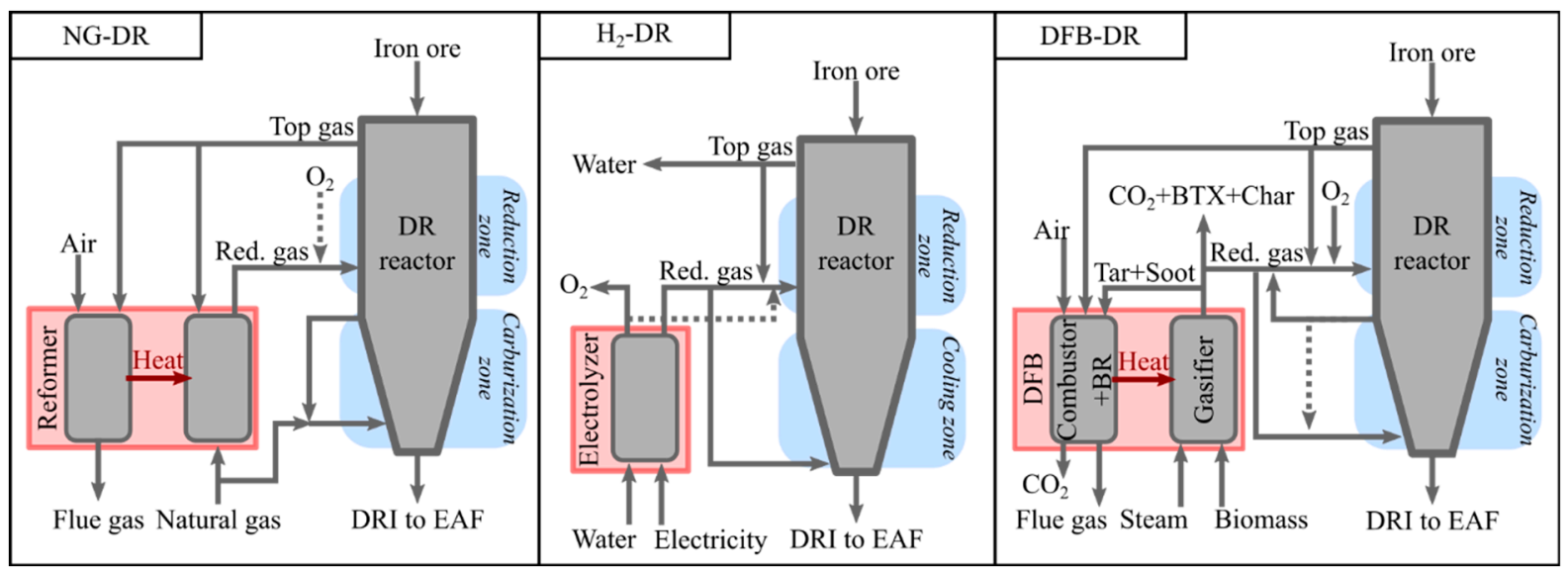

Figure 2. Schematic of the DR routes compared in this work. NG-DR refers to the traditional, natural-gas-based DR using the MIDREX technology, $\mathrm{H}_{2}$-DR refers to DR using hydrogen produced from electrolysis, and DFB-DR refers to the DR of iron using gas derived from DFB biomass gasification. The $\mathrm{H}_{2}$-DR and DFB-DR routes are based on a MIDREX DR reactor. Red. gas refers to the reducing gas, and $B R$ refers to the bed reducer.

For the DFB-DR case, the cold gas from the gasification of biomass is used as both the reducing gas and carburizing gas, as indicated by the split arrows going to the carburization and reduction zones in the right-hand panel in Figure 2. The carburizing gas can be partly recirculated, as shown by the dashed arrow, and the remainder is mixed with the reducing gas. Not all of the top-gas is recirculated, as the reduction of the slag bed material requires diversion of part of the top-gas to the bed reducer, represented by the arrow going from the top-gas to the "Combustor + BR" box in the right-hand panel in Figure 2. In the bed reducer, the $\mathrm{H}_{2}$ and $\mathrm{CO}$ are oxidized, resulting in a nearly pure $\mathrm{CO}_{2}$ stream for sequestration. As the reduction of $\mathrm{Fe}_{2} \mathrm{O}_{3}$ with hydrocarbons, such as methane, is slow, the presence of hydrocarbons in the top-gas sent to the bed reducer is not desirable, as these hydrocarbons would have to be burnt with pure oxygen to obtain a pure $\mathrm{CO}_{2}$ stream. Similarly, the hydrocarbons are not expected to reduce the iron ore in the reduction zone of the DR reactor. Instead, they will merely act as a dilutant. For these reasons, the reducing gas introduced into the DR reactor should contain as low levels of hydrocarbons as possible.

Conversion of the hydrocarbons to syngas can be achieved through reforming or partial oxidation. The former requires the use of a catalyst, so to avoid the associated cost, partial oxidation (POX) may be preferred. Another argument for the use of POX is that, since the gasification gas must be cooled to remove tar and separate $\mathrm{CO}_{2}$, a significant amount of oxygen will anyway be needed to increase the temperature back to $1000{ }^{\circ} \mathrm{C}$, which is the inlet temperature of the DR. The production of pure oxygen can, therefore, be increased to meet, in addition, the demand for POX. Note that in the right-hand panel in Figure 2, for the sake of readability, only one oxygen input is represented. However, the oxygen input for POX occurs prior to the mixing of the reducing gas with the recirculated top-gas. Non-catalyzed POX is generally carried out at temperatures approaching $1400{ }^{\circ} \mathrm{C}$ [29]. Thus, significant amounts of $\mathrm{H}_{2}$ and $\mathrm{CO}$ will be oxidized to reach these temperatures. The pure oxygen needed for POX and to raise the temperature can be produced by air separation or water electrolysis. The latter option has the advantage of producing $\mathrm{H}_{2}$, which can be mixed in with the reducing gas to increase the DRI production. Note that, in addition to $\mathrm{CO}_{2}$ and char, some of the heavy hydrocarbons that need to be removed prior to $\mathrm{CO}_{2}$ separation can 
be high-value byproducts of the process. For example, benzene, toluene, and xylenes (BTX) are valuable chemical commodities that can be extracted and sold.

\section{Description of the Proposed System}

In this section, the layout of the system proposed in this work and introduced in Section 2.3 is described in greater detail. This description is restricted to the DR reactor in the steel production chain since the operation of the EAF and subsequent units will not significantly differ from the traditional DRI-EAF route. Still, it is worth noting that heat integration possibilities may differ and that, in comparison to the $\mathrm{H}_{2}$-DR case, the DRI is carburized. Furthermore, biochar, which may be needed in the EAF, is inherently produced by the DFB process.

The layout of the DFB-DR section of the steel mill is shown in Figure 3. This section is conceptually divided into three sub-sections: (1) the DFB loop, including the bed reducer, as well as the fuel dryer, and steam and air preheating; (2) the DR reactor; and (3) the gas-handling section. The latter includes all the cleaning, upgrading, separation, and preheating steps for the raw gas from the gasifier, the top-gas from the DR reactor, and the $\mathrm{H}_{2}$ gas from electrolysis. The electrolyzer itself is not a part of any of these three sections. The $\mathrm{H}_{2}$ stream from the electrolyzer is indicated as a dashed line in Figure 3 because the $\mathrm{O}_{2}$ required by the process can alternatively be produced by an ASU, in which case no $\mathrm{H}_{2}$ is available for the gas-handling section.

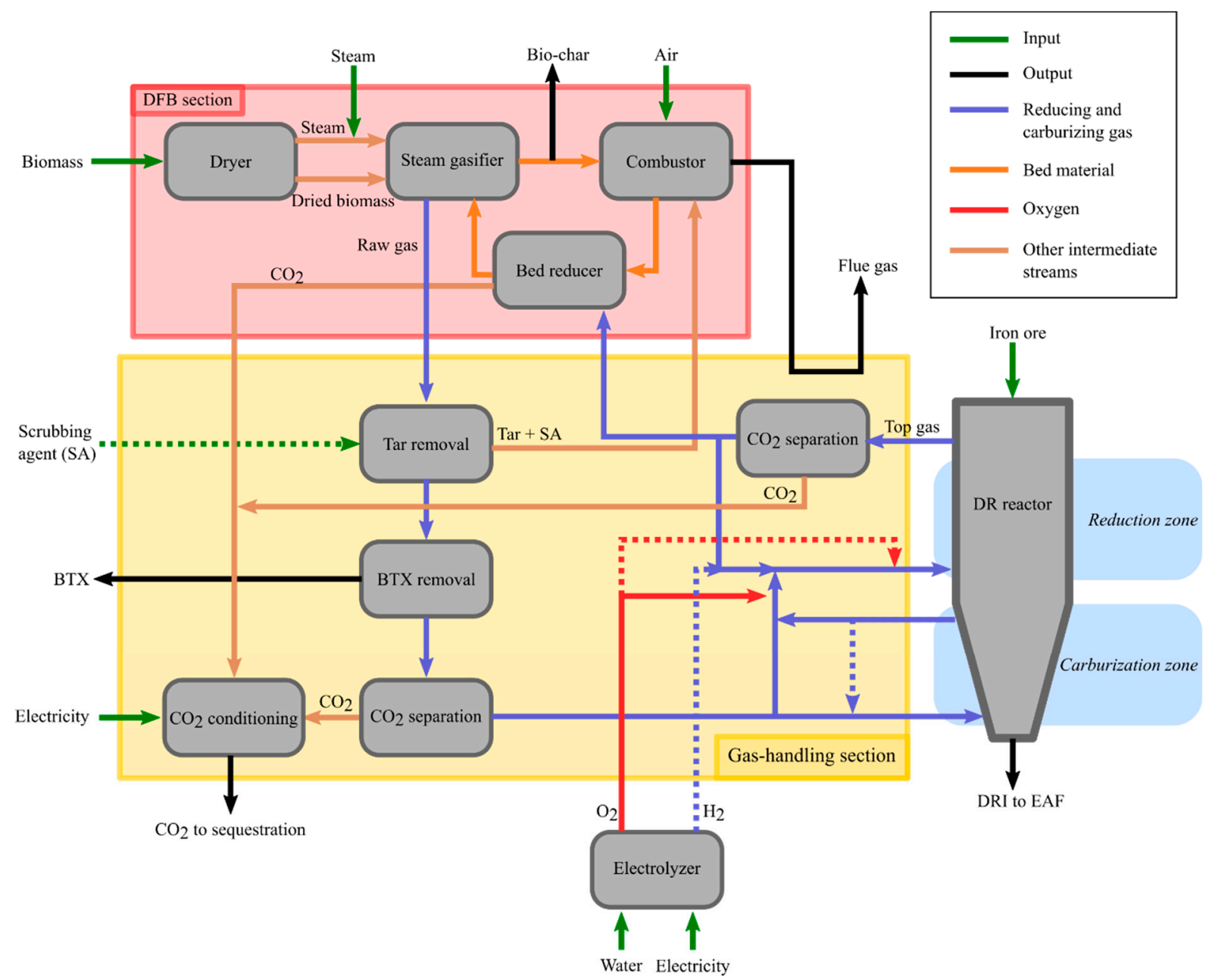

Figure 3. Schematic of the proposed DFB-DR route. The EAF section and downstream steel processing are not shown. Dashed lines indicate optional streams. The thicknesses of the arrows are not scaled to the sizes of the respective flows. 


\subsection{DR Process}

The DR reactor technology considered in this work is a shaft furnace, similar to the MIDREX process, in which the DRI is assumed to leave the DR reactor hot, to be fed directly into the EAF to decrease the energy consumption of that unit. As described in Section 2.1, the $\mathrm{DR}$ reactor requires the introduction of a reducing gas to reduce the iron ore to $\mathrm{Fe}$, as well as a carburization gas to ensure a carbon content that is optimal with regards to the end-use requirements, EAF operation, and energy consumption. The pressure requirement for the reducing gas used in the MIDREX process is only about 2 barg [30]. Consequently, and given that the DFB section does not require pressures higher than atmospheric pressure, the compression needs of the DFB-DR plant and the associated energy demand are low.

The light hydrocarbons formed during biomass gasification, such as methane and ethylene, can be used as carburization gas for the reduced iron. Therefore, it is desirable to retain the light hydrocarbons in the raw gas from the gasification reactor, instead of fully converting them to $\mathrm{H}_{2}$ and $\mathrm{CO}$ via steam or dry reforming, which is both costly and energy-intensive. In the MIDREX process, natural gas is used as the carburizing gas and to quench the hot DRI. The gas is extracted before the reduction zone and recirculated to the bottom of the furnace, as shown by the arrow in the left-hand panel in Figure 2. As the MIDREX process is taken as the reference for the DFB-DR process proposed in this work, it is assumed that the carburizing gas is also partially recirculated, with the remaining fraction being mixed with the reducing gas and transported to the reducing zone. In contrast to MIDREX, this carburizing gas is rich in $\mathrm{H}_{2}$ and $\mathrm{CO}$ and contains light hydrocarbons in addition to $\mathrm{CH}_{4}$, predominantly $\mathrm{C}_{2} \mathrm{H}_{4}$ and $\mathrm{C}_{3} \mathrm{H}_{6}$.

To maintain suitable reducing conditions that allow for extensive metallization of the iron ore, which is defined as the ratio of metallic iron to total iron, a certain reduction potential (RP) must be maintained within the reactor. This means that the gas introduced into the DR reactor must have sufficiently high partial pressures of $\mathrm{H}_{2}$ and $\mathrm{CO}$ to ensure reduction of the iron ore, as well as to ensure that the gas leaving the DR reactor, referred to as the top-gas, will still contain significant amounts of reducing gas. The $\mathrm{RP}$, also referred to as the gas quality, is typically qualitatively estimated according to the $\left(\mathrm{H}_{2}+\mathrm{CO}\right) /\left(\mathrm{H}_{2} \mathrm{O}+\mathrm{CO}_{2}\right)$ ratio [11,31]. Data from actual MIDREX plants, on which the NG-DR case is based, show a reducing gas input, sometimes referred to as bustle gas, with RP in the range of 8.7-12.3 and a top-gas with RP in the range of 1.7-2.5 [31,32]. Therefore, in this work, these RP values are used as references, and it is considered that the reducing gas should have an RP that is at least equal to 8.7, and the top-gas should have an RP that is at least equal to 1.7. That is not to say that an RP below these lower RP boundaries would not allow for significant reduction or would entail re-oxidation; rather, the reasoning is that efficient DR has been demonstrated for reducing and top gases with those characteristics and that the $\mathrm{H}_{2}$-DR and DFB-DR routes should aim to deliver a reducing gas and top gas of comparable or superior quality (in terms of RP). Note, however, that the RP of the top-gas will depend to a large extent on the $\mathrm{H}_{2} / \mathrm{CO}$ ratio of the reducing gas and the energy balance of the DR reactor.

To increase the production yield of metal iron, the top-gas should be recirculated to the DR reactor. However, to avoid the accumulation of $\mathrm{CO}_{2}$ and $\mathrm{H}_{2} \mathrm{O}$ in the reducing gas and a consequent decrease in the $\mathrm{RP}$, the steam is condensed and the $\mathrm{CO}_{2}$ is separated from the gas (upper " $\mathrm{CO}_{2}$ separation" box in Figure 3). Note that, prior to the $\mathrm{CO}_{2}$-separation step, dust, originating from the iron ore, must be removed from the top-gas. This step is not depicted in Figure 3. Due to the recirculation of the top-gas, the accumulation of inert or contaminant species could be a concern. Nonetheless, in the MIDREX process, two-thirds of the top-gas are recirculated to the reformer and, therefrom, to the DR reactor, which suggests that the accumulation of inerts and contaminants should not be an issue.

\subsection{Preparation of the Reducing and Carburization Gases}

The gas from DFB gasification is split into a reducing gas stream that is sent to the reducing zone of the DR reactor and a carburizing gas that is sent to the bottom of the furnace (Figure 3). However, the raw gas from the gasifier contains significant quantities 
of $\mathrm{CO}_{2}$, which would act as a dilutant for the reducing and carburizing gases, decreasing the RP of the former and possibly re-oxidizing the metallic iron in the case of the latter. Therefore, a $\mathrm{CO}_{2}$ separation step before the DR reactor is also required (the lower " $\mathrm{CO}_{2}$ separation" box in Figure 3).

The raw gas also contains heavy hydrocarbons, referred to as tar, which must be removed because they can lead to operational issues in the colder sections of the process, owing to their high boiling points [33]. This step is depicted as the "Tar removal" box in Figure 3. The removal of tar from the raw gas from the gasifier can be accomplished by scrubbing. For calculation purposes, it is assumed that rapeseed methyl ester (RME) is used as the scrubbing agent, as was used in the GoBiGas plant. The tar thus removed and the spent RME from the scrubbing process can be dealt with by burning them in the combustor of the DFB, thereby recovering energy, albeit with the loss of a small amount of $\mathrm{C}$ in the form of $\mathrm{CO}_{2}$. Some mono-aromatic hydrocarbons, such as BTX, are not removed by the RME scrubbing step. They can be removed by means of an active carbon bed. As described in Section 2.3, BTX are of high value and can be extracted as products of the process. Note that RME is expensive, so other tar-separation solutions will in practice likely be preferred, for instance, using self-cleaning heat exchangers [34] or other scrubbing agents, referred to as SA in Figure 3, which can also be produced inherently through the distillation of tar products [35].

As mentioned above, two $\mathrm{CO}_{2}$ separation steps must be performed, one before the introduction of the reducing and carburizing gas to the DR reactor and one thereafter. If MEA scrubbing, which is the state-of-the-art technology for $\mathrm{CO}_{2}$ capture, is used, the two scrubbing columns can use a single, shared reboiling column. The specific energy consumption for $\mathrm{CO}_{2}$ separation using MEA scrubbing is typically within the range of 3.5-4.0 MJ $/ \mathrm{kg} \mathrm{CO} 2$ for a combustion flue gas [36]. The $\mathrm{CO}_{2}$ concentrations in the cold gas and top-gas from which the $\mathrm{CO}_{2}$ is separated are $22 \%$ and $11 \%$, respectively, similar to typical flue gas $\mathrm{CO}_{2}$ concentrations. Additionally, both the raw gas and the top-gas will be at near-atmospheric pressure. Therefore, the specific energy consumption for $\mathrm{CO}_{2}$ separation in the proposed process will be within the abovementioned range. Although this energy demand is high, it is covered in the form of low-temperature (about $120^{\circ} \mathrm{C}$ ) heat, which can be provided by heat integration, given the substantial amounts of heat in the raw and flue gases from the DFB loop. This is, however, a matter of process optimization, as this heat can also be used for drying the fuel and preheating the streams.

\subsection{DFB Loop Operating Conditions}

The choices made regarding the temperature, degree of catalytic activity of the bed, and steam flow, which will affect both the residence time of the gas in the gasifier and the mixing behavior in the bed, will be an engineering trade-off with respect to the characteristics desired for the outputs from the gasifier. The degree of char gasification targeted will depend on how valuable the biochar is compared with the steel, since a higher degree of gasification will increase the production of $\mathrm{H}_{2}$ and $\mathrm{CO}$, and, thereby, increase the production of DRI. High temperature and high bed catalytic activity will enhance the gasification rate. They will also decrease the tar yield, thereby reducing the demand for scrubbing agent in the tar-removal step. These conditions also promote the reforming of hydrocarbons to $\mathrm{H}_{2}$ and $\mathrm{CO}$. On one hand, this will increase the amount of reducing gas available to the DR process. On the other hand, it will decrease the levels of light hydrocarbons. Depending on how the kinetics of the carburization reactions (following R2 and R3) compare with the carburization with hydrocarbons, this might limit the degree of carburization.

It should be noted that intensifying the reactions in the gasifier, in particular via the use of a higher temperature, increases the heat demand of the DFB gasification process, which increases the demand for top-gas in the bed reducer. This, however, decreases the amount of reducing gas available for the DR reactor. Alternatively, or additionally (if using all the reducing gas from the top-gas is insufficient to reduce the bed), $\mathrm{H}_{2}$ must 
be provided from electrolysis, which increases the electricity consumption of the process, thereby decreasing its efficiency.

In light of these considerations, it is deemed preferable to operate the gasifier at the relatively low temperature of about $800^{\circ} \mathrm{C}$. Addition of promoters of catalytic activity, such as potassium salts, will likely not be necessary, since the reduced iron-rich bed material should provide a catalytic surface. Nevertheless, potassium salts may be added to promote gas-phase reactions and decrease the tar content, in the case that the contacts between the bed material and gas are insufficient, or during start-up if the iron-rich bed requires an activation period. Although oxygen addition to the gasifier is to be avoided, a level of oxygen transport from the bed reducer to the gasifier of about $5 \%$ of the stoichiometric demand for full combustion of the fuel is judged to be acceptable. This value corresponds to the level of oxygen transport in the GoBiGas plant using active olivine as the bed material, as estimated by Alamia et al. [37]. The reason for accepting a low level of oxygen transport is that it allows for the production of a highly concentrated $\mathrm{CO}_{2}$ gas from the bed reducer, with low $\mathrm{H}_{2}$ and $\mathrm{CO}$ concentrations, which can be sent to transport and storage after only limited conditioning. Indeed, if the bed were to be fully reduced, an excess of reducing gas would be needed in the bed reducer, which could result in a need to inject pure oxygen to polish the $\mathrm{CO}_{2}$-rich stream. The $\mathrm{CO}_{2}$ gas stream from the bed reducer is mixed with the $\mathrm{CO}_{2}$ from the two separation steps, and the formed stream is conditioned for transport and storage, as shown in Figure 3.

\subsection{Partial Oxidation and Combustion of Reducing Gas}

As noted in Section 2.3, partial oxidation of the hydrocarbons in the reducing gas is carried out prior to mixing with the recycled top-gas and the hydrogen produced from electrolysis (represented by the solid red $\mathrm{O}_{2}$ arrow meeting the cold gas arrow in Figure 3). Considering the relatively low concentrations of hydrocarbons in the reducing gas and that a temperature of about $1400{ }^{\circ} \mathrm{C}$ is required for non-catalyzed POX, large proportions of the $\mathrm{H}_{2}$ and $\mathrm{CO}$ are combusted, thereby producing $\mathrm{H}_{2} \mathrm{O}$ and $\mathrm{CO}_{2}$, and this decreases the reduction potential. This issue can be partly resolved by preheating the reducing gas using heat integration. The reducing gas, which is free of hydrocarbons, is then mixed with the recirculated top-gas and the hydrogen produced from electrolysis, with both of those streams being preheated by heat integration. If the temperature of the resulting stream is $<1000{ }^{\circ} \mathrm{C}$, a small amount of oxygen is added to bring the temperature up to $100{ }^{\circ} \mathrm{C}$, as indicated by the dashed red arrow in Figure 3.

\subsection{Electrolysis}

The pure oxygen required to raise the temperature of the reducing gas and for its partial oxidation is produced through the electrolysis of water. The choice of electrolysis rather than the less-energy-intensive ASU is based on two considerations: (1) the added hydrogen is fed to the DR reactor along with the reducing gas to increase the yield of reduced iron, as indicated by the dashed blue arrow going from the electrolyzer to the reducing gas in Figure 3, and (2) the reduction of the oxygen-carrying bed material in the DFB loop prior to the gasifier may require more reducing gas than may be available after the DR reactor. Note, however, that the choice between electrolysis and ASU for the production of oxygen is ultimately made based on economics, i.e., the price of electricity and the investment costs of the units. It is also possible to have in place both an ASU and an electrolysis plant and operate the latter when electricity prices are low or to over-dimension the electrolysis plant and operate it only during low-electricity-price periods and store the generated hydrogen and oxygen.

\section{Methods}

\subsection{Main Assumptions Related to the Mass and Energy Balances of the DFB-DR Route} 4.1.1. DFB Loop

The raw gas produced by the gasifier is given a composition that is based on the results of experiments carried out with active olivine in the Chalmers gasifier, as described 
previously [20]. The reason for this choice is that no experiments have been conducted in the Chalmers gasifier with an iron-rich bed that was reduced before entering the gasifier. Nonetheless, such a bed material would be expected to have a very high catalytic activity, due to its concentrations of iron and calcium. Consequently, it is assumed that its activity would be similar to that of the most active olivine case tested in the Chalmers gasifier.

The heat of oxidation of the bed material was based on the $\mathrm{Fe}_{2} \mathrm{O}_{3} / \mathrm{Fe}_{3} \mathrm{O}_{4}$ couple, corresponding to $-476 \mathrm{~kJ} / \mathrm{mol} \mathrm{O}_{2}$. This choice may seem to contradict the results of Hildor et al. [26], who studied the oxygen-carrying behavior of BF-BOF slag and found that the couple involved in oxygen transport was $\mathrm{Fe}_{3} \mathrm{O}_{4} / \mathrm{FeO}$, corresponding to a heat of oxidation of $-627 \mathrm{~kJ} / \mathrm{mol} \mathrm{O}_{2}$. However, they also reported that the $\mathrm{Fe}_{3} \mathrm{O}_{4}$ and $\mathrm{FeO}$ phases included dopants such as $\mathrm{Mg}$ and $\mathrm{Mn}$. The presence of these dopants likely alters the heat of oxidation of the material. Given that the heat of oxidation of the slag considered for bed material in the present work is not known, and considering that a heat of oxidation of $-627 \mathrm{~kJ} / \mathrm{mol} \mathrm{O}_{2}$ is relatively high compared with the heat of oxidations of typical oxygen carriers considered for chemical-looping applications [22], the choice of using a value of $-476 \mathrm{~kJ} / \mathrm{mol} \mathrm{O}_{2}$ (based on the $\mathrm{Fe}_{2} \mathrm{O}_{3} / \mathrm{Fe}_{3} \mathrm{O}_{4}$ couple) is deemed reasonable. This value will lead to a conservative estimate of the level of oxygen transport required for autothermal operation of the process.

Based on the aforementioned experiments, a temperature of $810^{\circ} \mathrm{C}$ is assumed for the gasifier. The combustor is assumed to be operated at $860^{\circ} \mathrm{C}$. The bed material entering the bed reducer is assumed to be at a temperature of $835^{\circ} \mathrm{C}$, i.e., the average of the temperatures in the gasifier and combustor. The fraction of the top-gas remaining after $\mathrm{H}_{2}$-separation that is sent to the bed reducer is assumed to be at room temperature. Despite this large temperature difference, the high thermal inertia of the circulating bed ensures that the temperature of the bed does not drop below the temperature assumed for the gasifier.

The degree of gasification of the char in the gasifier is set at $20 \%$. The degree of gasification is a function of the combined influences of several factors, mainly the temperature but also the bed catalytic activity and the circulation rate of the bed. The $20 \%$ value is meant to reflect that the low temperature will not be conducive to a high gasification rate but that some degree of gasification is to be expected, in particular due to catalytic effects.

In addition to these assumptions, other minor assumptions are made that have an influence on the performance of the DFB loop. In the gasifier, a steam-to-fuel ratio of $0.80 \mathrm{~kg}$ steam $/ \mathrm{kg}$ (on a dry, ash-free basis) fuel is assumed. This value includes the moisture of the fuel recovered from the dryer, which is assumed to dry the fuel completely, using heat from the raw gas and flue gases. The heat from the raw gas and flue gas is also used to preheat the air and steam fed to the combustor and gasifier, respectively, to a temperature of $350^{\circ} \mathrm{C}$, which was the preheating level in the GoBiGas plant. The combustor is assumed to operate with an excess oxygen ratio of $1.2\left(\mathrm{~mol} \mathrm{O}_{2} / \mathrm{mol}\right.$ stoichiometric $\mathrm{O}_{2}$ demand). Finally, the mixture of tar and spent RME burnt in the combustor is assumed to enter at room temperature, meaning that this stream is not preheated, since the low volume flow does not justify the installation of a heat exchanger. It is important to recall that the RME is only used as a model of a generic scrubbing agent for the mass and energy balances. The consumption of the scrubbing agent is based on the RME consumption of the GoBiGas plant, corresponding to $0.03 \mathrm{MW} / \mathrm{MW}$ fuel. It should be noted that this means that the scrubbing agent flow is not proportional to the amount of tar.

\subsubsection{Gas-Handling Section}

The separation of $\mathrm{CO}_{2}$ from the hydrocarbon-rich gas is assumed to be achieved by MEA scrubbing, with a specific energy consumption of $3.5 \mathrm{MJ} / \mathrm{kg} \mathrm{CO}_{2}$, i.e., the lower limit of the aforementioned 3.5-4.0 MJ $/ \mathrm{kg} \mathrm{CO}_{2}$ range, based on the assumption that the energy consumption of MEA scrubbing from flue gas will, in the future, be decreased such that $3.5 \mathrm{MJ} / \mathrm{kg} \mathrm{CO}$ will be a conservative value. The temperature of the scrubbing column is assumed to be $40{ }^{\circ} \mathrm{C}$ and that of the reboiling column is assumed to be $120{ }^{\circ} \mathrm{C}$. The 
separation efficiency of $\mathrm{CO}_{2}$ is assumed to be $95 \%$ and the purity of the $\mathrm{CO}_{2}$ stream is assumed to be $100 \%$.

The gas-handling section receives all the useful heat from the DFB section, i.e., from the raw gas and flue gas, as well as the heat from the top-gas. The heat balance of the process shows that these heat sources are sufficient to cover the heat demand for $\mathrm{CO}_{2}$ separation and the preheating demand of the reducing gas prior to its partial oxidation, the recirculated top-gas and the hydrogen from electrolysis, and the carburizing gas. The preheating temperature of these three streams is assumed to be $600{ }^{\circ} \mathrm{C}$. The reducing gas and top-gas are preheated from $40{ }^{\circ} \mathrm{C}$, which is the assumed temperature of the MEA scrubber, and the hydrogen from electrolysis is preheated from $70^{\circ} \mathrm{C}$. A proper heat integration study would account for the temperature level of the heat sources and the heat demands. However, such an exercise was deemed to be outside the scope of the present study. Nonetheless, the heat demand for $\mathrm{CO}_{2}$ separation dominates the heat demand in the gas-handling section, and this demand is at a low temperature level, which suggests that heat integration will be feasible.

\subsubsection{DR Reactor}

The DR reactor is modeled as a black box that consists of two zones. At the bottom of the reactor is the carburization zone, where the carburizing gas is introduced at $600^{\circ} \mathrm{C}$, which is also the temperature that is assumed for the DRI extracted from the furnace. The carburizing gas reacts with $\mathrm{Fe}$ to form $\mathrm{Fe}_{3} \mathrm{C}$ and is then extracted before the second zone. A carbon content of $2 \% \mathrm{wt}$ is assumed to be achieved, and, for the sake of simplification, all the carbon is assumed to be in the form of $\mathrm{Fe}_{3} \mathrm{C}$, meaning that no free carbon is formed. The conversion of hydrocarbons via R1 is arbitrarily set to $50 \%$, and the rest of the carbon comes from R2 and R3, with half of the CO assumed to react via R2 and the other half via $\mathrm{R} 3$. The recycling rate of the hydrocarbons is arbitrarily set to $50 \%$. This recycling rate is chosen because it results in a carburization gas with an $\mathrm{RP}$ of 8 . This ensures that accumulation of $\mathrm{H}_{2} \mathrm{O}$ and $\mathrm{CO}_{2}$ is limited and that the carburizing gas will not re-oxidize the reduced iron. These arbitrary values were verified, by a sensitivity analysis, to have negligible impacts on the results of the work.

Located above the carburization region is the reduction zone, wherein iron ore, assumed introduced as pellets, is reduced to Fe. A metallization degree of $92 \%$ is assumed, meaning that $8 \%$ of the iron in the DRI is in the form of $\mathrm{FeO}$. The reducing gas is assumed to be introduced at a temperature of $1000{ }^{\circ} \mathrm{C}$ and exits as the top-gas at $350{ }^{\circ} \mathrm{C}$. Iron ore is introduced at the top of the furnace at room temperature. The reduction reactions are assumed to occur with $\mathrm{H}_{2}$ and $\mathrm{CO}$ in proportion to their relative concentrations in the gas. No re-oxidation with $\mathrm{H}_{2} \mathrm{O}$ or $\mathrm{CO}_{2}$ is assumed, and no slippage of hydrocarbons from the carburization zone is considered. The composition of the top-gas is modified to account for the water-gas shift (WGS) reaction, the exothermic nature of which is also accounted for in the DR reactor heat balance. Rather than setting it to equilibrium, it is assumed that the WGS reaction will reach a quotient of reaction equal to 2.5 , which corresponds to the average of the values recorded in the top-gases of the Gilmore and Contrecoeur NG-DR plants [31]. The heat losses from the DR reactor walls to the surrounding are assumed to be equal to $2.5 \%$ of the energy content of the iron, expressed here as the heat of oxidation of $\mathrm{Fe}$ to $\mathrm{Fe}_{2} \mathrm{O}_{3}$.

\subsubsection{Electrolyzer}

The electrolyzer is assumed to provide the oxygen required for the partial oxidation of the reducing gas and to raise its temperature prior to introduction into the DR reactor. The electrolysis efficiency is assumed to be $75 \%$, based on typical values for state-of-the-art electrolyzers [38]. The operating pressure and temperature are assumed to be atmospheric and $70{ }^{\circ} \mathrm{C}$, respectively. 


\subsubsection{Electric Arc Furnace}

The EAF and downstream steel-processing steps are not included in the mass and energy balances in this work. However, the EAF unit is included in the calculation of the total production cost of liquid steel (LS). It is assumed that the EAF is entirely charged with DRI, i.e., no scrap is fed into it. The choice to not include scrap in the charge to the EAF is motivated by the desire to have a direct relationship between the amount of steel produced and the consumption of biomass and electricity in the DFB-DR process. The electric energy consumption of the EAF is thus about $570 \mathrm{kWh} / \mathrm{t}$ steel, based on the value used by Kirschen et al. [16]. As the DRI is hot-charged to the EAF, the energy consumption is decreased. It is assumed that the electricity demand is reduced by $120 \mathrm{kWh} / \mathrm{t}$ steel when the DRI is charged at $600{ }^{\circ} \mathrm{C}$, in line with the experience reported for the hot-charging of DRI [14]. The steel produced is assumed to have a carbon content of $0.2 \%$ wt. For the sake of simplicity, all the iron introduced with the ore is assumed to end up in the LS. This means that losses in the form of fines and, more importantly, in the slag, are neglected. Note that the oxygen input to the EAF is not included in the oxygen demand of the process.

\section{2. $\mathrm{NG}-\mathrm{DR}$ and $\mathrm{H}_{2}-\mathrm{DR}$ Comparison Cases}

\subsubsection{NG-DR}

The NG-DR case is built upon data obtained from existing and decommissioned MIDREX plants, in particular the Contrecoeur plant in Montreal, Quebec, Canada, and the Gilmore plant in Portland, Oregon, USA, using the data from Béchara et al. [31], as well as the data from the SIDERCA plant in Campana, Buenos Aires, Argentina [32]. Table 1 shows the compositions of the reducing gas and top gas in these plants. The natural gas consumption of the NG-DR case is based on that of the Contrecoeur plant, corresponding to $2.6 \mathrm{MWh} / \mathrm{t}$ iron. This is the amount of natural gas consumed in the reformer, as well as a small fraction (about $7 \%$ ) that is combusted with air to raise the temperature of the reducing gas after the reformer. Here, it is assumed that the heat demand of the reformer is entirely covered by the top-gas, about one-third of which is combusted, with two-thirds being recycled to the reformer, based on the Gilmore data. Only the reducing zone section of the DR reactor is considered, as information on the level of natural gas consumption in the carburization zone and the recycling rate of the carburizing gas could not be found.

Table 1. Characteristics of the reducing gas and top-gas for the three NG-DR reference plants [31,32].

\begin{tabular}{|c|c|c|c|c|c|c|}
\hline Plant & $\mathrm{H}_{2}(\% \mathrm{vol})$ & CO (\%vol) & $\mathrm{H}_{2} \mathrm{O}$ (\%vol) & $\mathrm{CO}_{2}(\% \mathrm{vol})$ & $\mathrm{H}_{2} / \mathrm{CO}$ & $\mathbf{R P}$ \\
\hline \multicolumn{7}{|c|}{ Reducing gas } \\
\hline Contrecoeur & 49.7 & 32.7 & 4.3 & 2.4 & 1.5 & 12.3 \\
\hline Gilmore & 52.6 & 30.0 & 4.7 & 4.8 & 1.8 & 8.7 \\
\hline Siderca & 52.9 & 34.7 & 5.2 & 2.5 & 1.5 & 11.5 \\
\hline \multicolumn{7}{|c|}{ Top gas } \\
\hline Contrecoeur & 40.3 & 19.6 & 19.0 & 17.1 & 2.1 & 1.7 \\
\hline Gilmore & 46 & 21 & 11 & 16 & 2.2 & 2.5 \\
\hline
\end{tabular}

\subsection{2. $\mathrm{H}_{2}$-DR Case}

The $\mathrm{H}_{2}$-DR case (Figure 2) is built upon simple considerations of the mass and energy balances. The assumptions made for the temperature and efficiency of the electrolyzer are the same as those for the DFB-DR case (see Section 4.1.4). It is assumed that the reducing gas, which consists of the $\mathrm{H}_{2}$ produced from electrolysis and the top-gas and which is entirely recycled, can be preheated to $350{ }^{\circ} \mathrm{C}$, which is the temperature assumed for the top-gas. About $10 \%$ of the hydrogen in the reducing gas must be burnt subsequently to raise the temperature to $1000{ }^{\circ} \mathrm{C}$, using pure oxygen, which is a by-product of the electrolysis. Table 2 shows the compositions and reduction potentials of the reducing gas and top-gas for the $\mathrm{H}_{2}$-DR case. As the reducing gas has an RP comparable to that of the Gilmore MIDREX plant, it can be deemed sufficient for extensive reduction of the iron ore. 
The composition of the top-gas is determined so as to achieve an RP of 3. This RP value is established based on the heat balance of the reduction zone of the DR reactor, where the DRI is assumed to exit the reactor at $600{ }^{\circ} \mathrm{C}$. The higher RP value compared with the NG-DR case reflects the fact that reduction of $\mathrm{Fe}_{2} \mathrm{O}_{3}$ with $\mathrm{H}_{2}$ is endothermic, whereas with $\mathrm{CO}$, it is exothermic. Thus, a lower $\mathrm{H}_{2} / \mathrm{CO}$ ratio of the reducing gas decreases the endothermicity of the reduction reaction, thereby increasing the DRI yield per unit energy of reducing gas input. The level of $\mathrm{H}_{2}$ consumption of the process is estimated to be 2.8 $\mathrm{MWh}_{2} / \mathrm{t}$ iron, corresponding to $84 \mathrm{~kg} \mathrm{H}_{2} / \mathrm{t}$ iron.

Table 2. Characteristics of the reducing gas and top-gas for the $\mathrm{H}_{2}$-DR case.

\begin{tabular}{cccc}
\hline & $\mathbf{H}_{\mathbf{2}} \mathbf{( \% \mathbf { o o l } )}$ & $\mathbf{H}_{\mathbf{2}} \mathbf{O}(\% \mathbf{v o l})$ & $\mathbf{R P}$ \\
\hline Reducing gas & 89.8 & 10.2 & 8.8 \\
Top gas & 75.0 & 25.0 & 3.0 \\
\hline
\end{tabular}

\subsection{Performance Indicators}

The performances of the various routes for the production of DRI are compared in this work. The energetic performance of the system can be assessed in a multitude of ways. The approach chosen in this work is to establish energy efficiency performance indicators based on chemical and electrical energy terms, which means that sensible and latent heat terms are excluded from the definitions. The rationale for this choice is that the sensible and latent heat terms will depend on specific temperature levels and heat integration possibilities for the system, whereas relying solely on chemical energy terms reflects the higher-level design choices for the system, i.e., which reactors and separation steps are chosen rather than the specific details of their operation. The chemical energy terms are defined as the lower heating value for combustible streams and as the heat of oxidation for the reduced iron. The efficiency performance indicators are defined in Table 3, and the subscripts used to describe the energy terms in these definitions are explained in Table 4.

Table 3. Definitions of the efficiency performance indicators. All the efficiencies are based on chemical and electrical energies, i.e., the sensible and latent heat terms are not part of these definitions, except for $\varepsilon_{D F B, 3}$, which includes the sensible heat demand for reboiling the MEA. Subscripts are defined in Table 4.

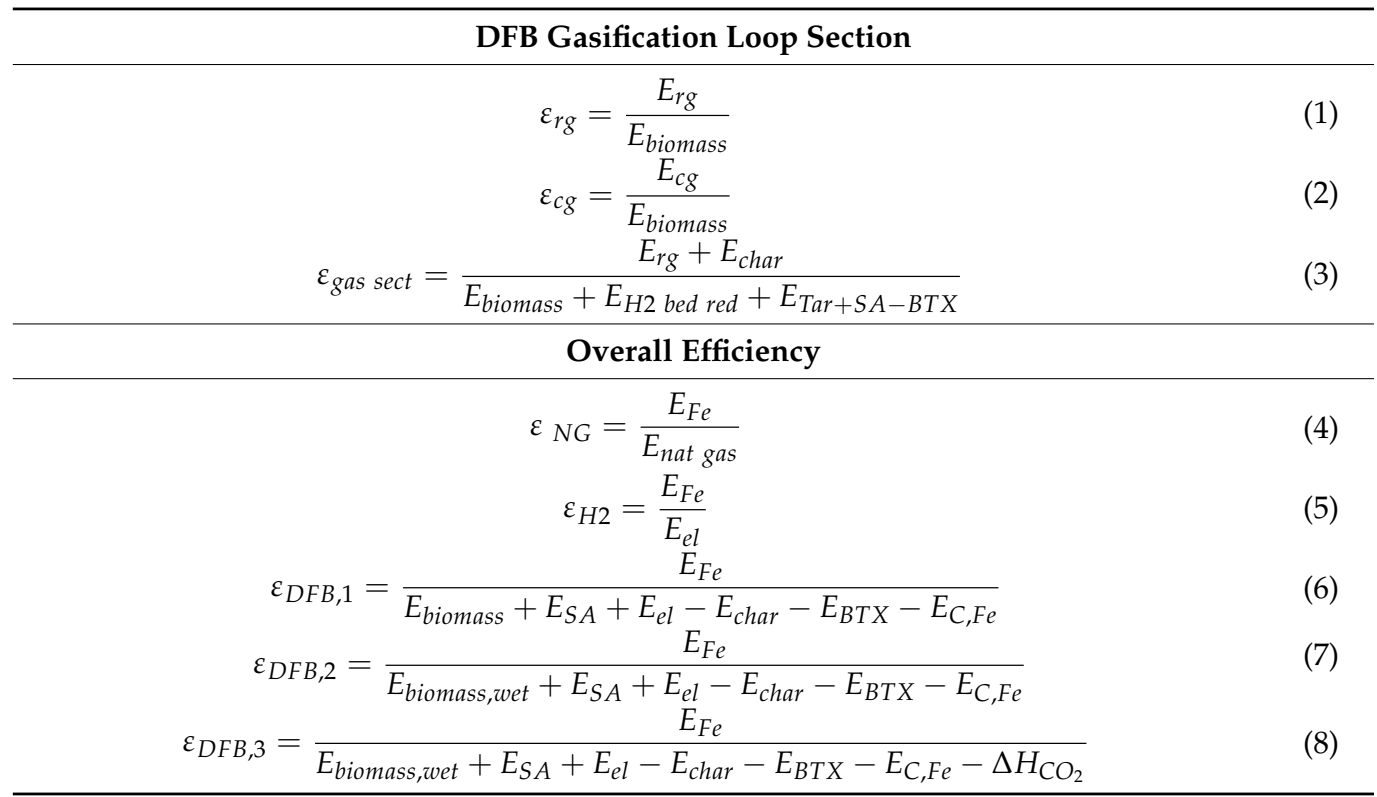


Table 4. Definitions of the subscripts used in the definitions of the efficiency performance indicators in Table 3.

\begin{tabular}{|c|c|}
\hline Subscript & Definition \\
\hline biomass & Energy content of the biomass on a dry basis \\
\hline biomass, wet & Energy content of the biomass on a wet basis \\
\hline BTX & Energy content of the BTX \\
\hline $\mathrm{C}, \mathrm{Fe}$ & Energy content of the carbon in the iron, in the form of $\mathrm{Fe}_{3} \mathrm{C}$ \\
\hline $\mathrm{cg}$ & Cold gas (tar-free raw gas) \\
\hline el & Electricity input to the electrolyzer \\
\hline $\mathrm{Fe}$ & Energy content of the reduced iron, set as equal to the heat of oxidation \\
\hline gas sect & Gasification section \\
\hline $\mathrm{H}_{2}$ bed red & Hydrogen-rich gas to bed reducer \\
\hline red gas & Reducing gas \\
\hline$r g$ & Raw gas (contains tar) \\
\hline$S A$ & Scrubbing agent \\
\hline$T A R+S A-B T X$ & $\begin{array}{l}\text { Mixture of tar and scrubbing agent from the tar separation step (not } \\
\text { including BTX) }\end{array}$ \\
\hline
\end{tabular}

Before defining and comparing the efficiencies of DRI production for the various routes, the efficiency of the gasifier of the DFB-DR case is determined to compare it with the efficiency of the GoBiGas gasifier [39]. Two main efficiencies can be defined. The first, shown in Equation (1), is the raw gas efficiency $\varepsilon_{r g}$, which corresponds to the energy content of the biomass that was converted to the hot raw gas, i.e., including tar. The second efficiency performance indicator is the cold gas efficiency. It corresponds to the ratio of the energy content of the tar-free cold gas to the energy content of the biomass, as shown in Equation (2). One additional efficiency performance indicator of interest, shown in Equation (3), is the gasification section efficiency. It corresponds to the ratio of the energy content of the two outputs from this section, i.e., the raw gas and the char, to the (chemical) energy content of all the inputs to that section, i.e., the biomass fuel, the hydrogen-rich gas to the bed reducer, and the mixture of tar and scrubbing agent from the tar separation step. It cannot be directly compared with the gasification section efficiency of the GoBiGas plant, as the DFB configuration is different, in that the GoBiGas reactor does not have a bed reducer that is fed with reducing gas and does not use an oxygen-carrying bed material.

The overall DRI production efficiency can be defined for each of the three routes, NG-DR, $\mathrm{H}_{2}$-DR, and DFB-DR, as the ratio of the energy content of the reduced iron to the energy content of the inputs to the DR plant. The energy content of the iron is defined as the heat of oxidation of $\mathrm{FeO}_{x}$ to $\mathrm{Fe}_{2} \mathrm{O}_{3}$, where $\mathrm{FeO}_{\mathrm{x}}$ is the average composition of the reduced iron. In this work, it is assumed that a metallization degree of $92 \%$ is reached in all the cases, such that the energy content of the iron is $391 \mathrm{~kJ} / \mathrm{mol}$ or $1.9 \mathrm{MWh} / \mathrm{t}$. The overall efficiency of the NG-DR route is simply the ratio of the energy content of iron to that of the natural gas input. Some DR plants use an ASU to provide pure oxygen for raising the temperature of the reducing gas. The associated electrical energy demand is not accounted for in the overall efficiency, and other electrical demands, for instance for fans, are neglected. For the $\mathrm{H}_{2}$-DR route, the overall efficiency of the DRI production is the ratio of the energy content of iron to the electricity input to the electrolyzer, where once again other electrical demands are neglected.

For the DFB-DR route, the energy inputs are the biomass, the scrubbing agent (if any), and the electricity provided to the electrolyzer. Note that the energy content of the MEA scrubbing agent used for the $\mathrm{CO}_{2}$ separation is not included. Since the extracted char and BTX do not represent losses, their energy contents are removed from the energy inputs. Similarly, as the DFB-DR route defined here includes energy inputs that will become carbon-bound as $\mathrm{Fe}_{3} \mathrm{C}$, the energy content of that carbon is subtracted from the denominator of $\varepsilon_{D F B, 1}$. Two modified versions of this efficiency are additionally defined. The first, $\varepsilon_{D F B, 2}$, accounts for the fact that an advantage of the DFB gasification process is that wet fuels can be used, whereby heat from the DFB flue gas or raw gas provides 
heat for drying the fuel, with the generated steam being used in the process. As such, the efficiency $\varepsilon_{D F B, 1}$ can be recalculated using the energy content of the biomass on a wet basis. The second modified efficiency, $\varepsilon_{D F B, 3}$, accounts for the fact that part of the energy input is converted to heat that is then used to cover the heat demand of the MEA reboiling column, translating into the production of $\mathrm{CO}_{2}$ for sequestration, representing a valuable product of the DFB-DR route. If this heat is not used for $\mathrm{CO}_{2}$ separation, it can be used to optimize the process, notably via preheating, and thereby increase the efficiency. To account for this, $\varepsilon_{D F B, 2}$ is modified to incorporate this valuable heat, which covers the MEA reboiler heat demand and should not be considered a loss, in the form of $\Delta H_{\mathrm{CO}_{2}}$ in $\varepsilon_{D F B, 3}$.

\subsection{Assumptions Made for the Economic Calculations}

This section describes the assumptions that are made during the derivation of the economics of the three routes. In this work, the DR routes are initially compared on the basis of the reducing gas cost. The DR furnace is a highly flexible reactor that can accommodate a wide range of compositions of the reducing gas. Therefore, comparing the costs of the reducing gas, in EUR/MWh, is a way to compare the economic feasibility levels of the DR routes. The total production costs of the LS, expressed in EUR/t LS, are also compared for the three routes, as well as for the traditional BF-BOF route, as they reflect the actual costs for the steel produced using these technologies. For the $\mathrm{H}_{2}$-DR and NG-DR routes, the cost related to the production of reducing gas is calculated based only on the electrolyzer and the reformer, respectively, since other costs are assumed to be negligible in comparison. The capital expenditures (CAPEX) and operational expenditures (OPEX) for the electrolyzer are set to be the same (per unit energy) for both the $\mathrm{H}_{2}$-DR and DFB-DR routes.

\subsubsection{Investment Cost}

This section describes the capital expenditures related to the compared DR routes. The EAF is included in the calculation of the total production cost of LS only, although the downstream steel processing units are not included. The CAPEX is given as the total investment cost in millions of euros (MEUR), as a cost that is relative to the yearly LS production capacity, and as an annualized cost, based on a weighted average cost of capital (WACC) of 5\%, a lifetime of 20 years for all the items of equipment, and a plant that operates at 8000 full-load hours in a year. All costs are calculated in EUR for Year 2020.

\section{DFB Loop and Gas-Handling Section}

The investment costs of the DFB loop and the gas-handling section are derived from the economic assessment of an advanced biofuel production (ABP) plant by Thunman et al., which was based on the economic data from the GoBiGas project [35]. In the present study, the plant is scaled to fit the needs of a $1 \mathrm{Mt} /$ year steel plant based on the DRI-EAF route. The upscaling of the cost data for the GoBiGas plant, which had a biomass input of $32 \mathrm{MW}$, is performed using the scaling factors provided in the work of Thunman et al. [35]. Some differences in design exist between the ABP plant and the DFB loop and the gas-handling section of the present study.

The first main design difference is in the DFB loop itself, which in the present study includes a bed reducer that is absent from the ABP plant design. The proposed bed reducer will be a fluidized section that is relatively small compared with the gasifier and combustor. The main cost associated with these process units is the cost of the refractory. Even though the proposed bed reducer will have a higher surface-to-volume ratio than the gasifier or combustor, entailing a greater need for refractory proportional to its size, it is likely to be small enough that the cost of the DFB loop will not increase significantly.

A second major difference in design corresponds to the synthesis section of the ABP plant, which is not present in the proposed process. The avoided costs are related to the compression of the cold gas from gasification, and the olefin hydrogenation, premethanation, and methanation steps in the ABP plant design. For a 100-MW biomass input $\mathrm{ABP}$ plant, the total cost related to these units can be roughly estimated using a Lang Factor, 
which relates the total investment cost of a unit to its delivered cost, and the Lang Factor value of which is around 5 for fluid processes [40]. To be conservative and not overestimate the cost reduction linked to the absence of these units, a Lang factor of 4 is used. The avoided costs correspond to $33 \%$ of the total cost of the ABP plant for the 100-MW case. It is assumed that the same decrease in cost would be obtained at larger scales.

The proposed process will have a $\mathrm{CO}_{2}$ separation system that is comparable to that of the ABP plant, with two MEA scrubbing columns sharing a single MEA reboiling column. However, it will also have a $\mathrm{CO}_{2}$ liquefaction unit. The cost of the $\mathrm{CO}_{2}$ liquefaction unit will be made up mostly of the cost of compressors. It is assumed that the added cost of the $\mathrm{CO}_{2}$ liquefaction unit, relative to the ABP plant, will be low compared with the avoided cost of the synthesis section. Additionally, the gas-handling section of the present study will likely require a much higher level of heat integration than the ABP plant, due in part to the necessity to preheat the gases introduced into the DR reactor. Although this cost can be substantial, it will likely be low in comparison with that of the synthesis section.

Based on these considerations, the overall cost of the DFB loop and the gas-handling section of the DFB-DR route will be determined based on the cost of the ABP plant, reduced by a factor of $20-30 \%$. This range is conservative, as it likely underestimates the savings related to the avoided synthesis section. It is also important to consider that, as with any economic estimate, this figure is small in comparison with other cost variations that exist between projects. Note that in the economic assessment of the ABP plant, a steam cycle and a belt dryer, which were not present in the GoBiGas design, are added. These two units are also included in the proposed system. The corresponding costs for a $100 \mathrm{MW}$ substitute natural gas plant are given. The scale factors are arbitrarily assumed to be 0.60 , 0.70 , and 0.80 , for the low, medium, and high scale factors, respectively, based on the scale factor of 0.67 given in Table 4 of [35]

\section{DRI-EAF}

The CAPEX values for the DRI-EAF sections in the three DR routes are derived from [41], attributing a value of $370 \mathrm{EUR} / \mathrm{t}$ crude steel for the DR furnace, EAF, and auxiliary units (but not including the price for the indurated pellets production plant). For the DFB-DR and $\mathrm{H}_{2}$-DR routes, the reducing gas produced has a higher $\mathrm{H}_{2} / \mathrm{CO}$ ratio (infinite for the $\mathrm{H}_{2}$-DR case) than it has for the NG-DR route, on which the CAPEX for the DRI is typically based. As a higher $\mathrm{H}_{2} / \mathrm{CO}$ ratio means a more endothermic reduction reaction, the volume of gas needed to produce one tonne of DRI will be higher the higher the $\mathrm{H}_{2} / \mathrm{CO}$ ratio. Therefore, to produce the same amount of DRI, the DFB-DR, and especially the $\mathrm{H}_{2}-\mathrm{DR}$, will require a larger DR reactor. This, in turn, means that the specific cost of the DR reactor may slightly underestimate the cost of the reactor, as compared with the NG-DR case. Nonetheless, this discrepancy is not expected to have a significant impact on the total CAPEX and an even weaker impact on the total production cost of the steel, since at a large scale the OPEX and fuel cost are much higher than the annualized CAPEX.

\section{Electrolyzer}

The investment cost of the electrolyzer is based on Brynof et al. [38]. The cost estimation is based on the alkaline electrolyzer, which is by far the most mature technology. The corresponding investment cost is predicted to reach $700 \mathrm{EUR}_{2015} / \mathrm{kW}_{\text {elec }}$ in the near future (2030), according to the IEA [42].

\section{NG-DR Route Reformer Cost}

The investment cost of the reformer in the NG-DR route is derived from the cost of a natural gas steam reformer, i.e., $910 \mathrm{USD} / \mathrm{kW} \mathrm{H}_{2}$ or $770 \mathrm{EUR} / \mathrm{kW} \mathrm{H}_{2}$, as derived from a previous study [42]. Note that, at least in the case of the Gilmore plant from which much of the data for the NG-DR case is obtained, the reformer combines wet and dry reforming, with the $\mathrm{CO}_{2}$ coming from the recycled top-gas and the steam formed in situ by the reverse WGS reaction. This may generate small cost differences, which are deemed to be negligible. 
The cost of the reformer is given per $\mathrm{kW}$ of $\mathrm{H}_{2}$ produced, in the context of a plant that aims to produce pure hydrogen, meaning also that it involves a WGS step. Here, it is assumed that the cost of the reformer will be equivalent to $770 \mathrm{EUR}$ per $\mathrm{kW}$ of reformed gas produced. As most of the gas entering the reformer is recycled top-gas, the proportion of "reformed gas" per unit energy of reducing gas produced is assumed to be equal to the energy content of the reducing gas (given in MWh/t LS) minus the energy content of the top-gas recycled to the reformer. With this approximation, the "reformed gas" represents $42 \%$ of the reducing gas energy content of the Gilmore plant.

\section{BF-BOF Route}

The total production costs of liquid steel of the three DR routes are compared with the production cost of the traditional BF-BOF route. While brownfield investments are considered for the DR routes, the abundance of BF-BOF plants and the fact that it is the dominant technology mean that the DR routes must compete with BF-BOF plants that are only relined. The investment cost of relining a BF-BOF plant is set at $190 \mathrm{EUR} / \mathrm{t}$ annual production, derived from Wörtler et al. [43].

\subsubsection{Operating Expenditures}

In this section, the "fixed" operational expenditures, i.e., those that are assumed to remain constant from year to year, are described. Note that the prices for biomass and electricity are not included, whereas those for iron ore pellets and natural gas are included. The price of the iron ore pellets will affect all the DR routes equally. The price of natural gas fluctuates significantly over time, so a reasonable average price level for Sweden has been used.

\section{DFB Loop and Gas-Handling Section}

The operational costs for the DFB loop and the gas-handling section are also taken from the economic analysis of Thunman et al. [35]. To calculate the OPEX, reference values from the GoBiGas 32-MW biomass plant are used, along with the scaling factors provided, using the scaling law described in Equation (9), where $X$ is the biomass input (in MW) of the upscaled plant and $S F$ is the scaling factor. As the levels of consumables and waste products are directly proportional to the biomass input to the plant, their cost in EUR/MWh is not influenced by scale, so they do not follow the scaling law. The electricity-related cost is not considered, as it is assumed that the steam cycle will cover the electricity demand of the DFB loop and the gas-handling section, which does not include the electricity demand from the electrolyzer. Note that even though RME is used in the mass and heat balance calculations, its cost is not included in the economic calculation, since RME has a high price and would not be used as the scrubbing agent in a commercial unit. Instead, a cheaper scrubbing agent (possibly one distilled from its own tar) or other tar removal methods would be used, as described earlier. Table 5 details the various operating costs, which are given in EUR per MWh biomass input. The cost of the "Other" subcategory in the "Consumable and waste products" category in Table 5 is arbitrarily fixed at 1.5 EUR/MWh instead of the value of 4.5 EUR/MWh from the ABP plant, since the latter value is dominated by the price of methanation and WGS catalysts, which do not exist in the present process.

$$
C_{o p e, X M W}\left(\frac{\mathrm{EUR}}{M W h}\right)=C_{o p e, 32 M W} \cdot\left(\frac{32}{X}\right)^{1-S F}
$$

\section{DRI-EAF}

The price of iron pellets was derived from Pardo and Moya, who used a price of $133 \mathrm{EUR} / \mathrm{t}$ for Year 2010 and estimated the growth rate of the price until Year 2030 at $1.20 \%$ [44]. The price of the flux is set at $27 \mathrm{EUR}_{2010} / \mathrm{t}$, following the estimation of Fischedick et al. [45], who relied upon the data from Pardo and Moya [44]. Here again, an annual growth rate of $1.20 \%$ was used for the flux price. The consumption of flux 
in the DRI-EAF process was set to $58 \mathrm{~kg} / \mathrm{t}$ steel, based on previous data on lime consumption [46]. The amount and price of alloy were set to $11 \mathrm{~kg} / \mathrm{t}$ steel and $1777 \mathrm{EUR} / \mathrm{t}$, respectively, as selected by Vogl et al. [47], based on the data from Remus et al. [48] and Fischedick et al. [45]. The cost of replacing the graphite electrodes in the EAF is based on the assumptions reported by Vogl et al. [47], i.e., a consumption rate of $2 \mathrm{~kg} / \mathrm{t}$ steel and a price of $4 \mathrm{EUR} / \mathrm{kg}$. Finally, operation and maintenance costs equal to $3 \%$ of the CAPEX and labor costs of $38 \mathrm{EUR}_{2010} / \mathrm{t}$ are derived from Fischedick et al. [45].

Table 5. Operating expenses (in EUR/MWh biomass input) for the DFB loop and the gas-handling section. Adapted from [35].

\begin{tabular}{ccc}
\hline Operating Cost, Excluding Feedstock & Scale Factor & EUR/MWh for 32 MW Biomass Input \\
\hline Personnel & 0.1 & 18.1 \\
Maintenance & 0.67 & 9.0 \\
Consumable and waste products & & 2.5 \\
Electricity & & 0 \\
Activated carbon & & 1.0 \\
Other & 0.67 & 1.5 \\
Other costs & & 2.7 \\
\hline Total & & 32.3 \\
\hline
\end{tabular}

The cost of the various items described in the previous paragraph are adjusted from Year 2010 to Year 2020 using an average inflation rate of 1.3\%. The calculation of the individual cost items is shown in Equation (10):

$$
C_{j}\left(\text { EUR }_{2020} / \text { t steel }\right)=C_{j}\left(\text { EUR }_{2010} / \text { t steel }\right) \cdot(1+a)^{10} \cdot(1+i)^{10}
$$

where $j$ refers to a cost item, $a$ refers to the growth rate, which is fixed at $1.2 \%$ based on Pardo and Moya [44], and $i$ refers to the average inflation rate.

Electrolyzer

The "fixed" operational costs related to the electrolyzer and its operation are set to 3.5\% of the CAPEX, based on the data of Brynolf et al. [38]. The stack replacement costs, which typically make up 50\% of the CAPEX, are not included in the economic calculation.

\section{NG-DR Route: Steam Reformer OPEX and Natural Gas Price}

The fixed OPEX for the reformer is taken as 5\% of the CAPEX, based on the assumptions made in the IEA report [42]. The price for natural gas is set at a value of $22 \mathrm{EUR} / \mathrm{MWh}$, based on an average of the spot price of 16 EUR/MWh at Rotterdam, TTF over the period 2015-2020 [49] and accounting for pipeline transport costs of about 6 EUR/MWh, based on [50].

\section{BF-BOF Route}

For the BF-BOF route, the consumption rates of coking coal and natural gas in the plants are derived from Cavaliere [46] at $400 \mathrm{~kg} / \mathrm{t} \mathrm{LS}$ and $1.4 \mathrm{MWh} / \mathrm{t} \mathrm{LS}$, respectively. The price for the coking coal is derived from data from the IEA for the period 2016-2020, with prices ranging 75 to $310 \mathrm{USD} / \mathrm{t}$ [51]. The iron feedstock to the $\mathrm{BF}$ is assumed to be sinter fines, whose price in Sweden ranged 40 to 200 USD/t during the period 2010-2020, according to the SGU-Geological Survey of Sweden [52]. In the results shown in Section 5.5, only the production cost based on the median values of the ranges given for coal and sinter fines, corresponding to $170 \mathrm{EUR} / \mathrm{t}$ and $105 \mathrm{EUR} / \mathrm{t}$, respectively, is shown. For simplicity, the operation and maintenance costs and labor costs are set as equal to those of the NG-DR route, and the costs of flux and alloys are derived using the same cost data as described above, with consumption rates taken from Cavaliere [46]. Although there are certainly differences in operation and maintenance and labor costs between the two routes, these differences are dwarfed by the price fluctuations of the fuel and feedstock. The approach 
of using a median cost estimation for the production cost of the BF-BOF route is deemed reasonable, as the other routes will also be impacted by volatility in the prices of their fuel (energy sources and reducing agents) and feedstocks.

\subsubsection{Cost for the Reducing Gas}

Given the flexibility of the DR reactor, the main difference between the three DR routes lies in how the reducing gas is produced. Therefore, the easiest way to compare their economic feasibility levels is to compare the costs for production of the reducing gas. For the NG-DR route, this is determined by the cost of the reformer and the price of the natural gas. For the $\mathrm{H}_{2}$-DR route, the value is fixed based on the cost of the electrolyzer and the electricity price. For the DFB-DR route, the reducing gas cost is based on the costs for the DFB gasification loop and gas-handling section, as well as on the prices for biomass and electricity. The cost of the reducing gas considered in the DFB-DR case comprises the cost of the cold gas plus the cost of the hydrogen produced from electrolysis.

4.4.4. Biomass and Electricity Prices, Revenue from Negative $\mathrm{CO}_{2}$ Emissions, and Total Liquid Steel Production Cost

The economic feasibilities of the DFB-DR and $\mathrm{H}_{2}$-DR routes are assessed based on a range of electricity and biomass prices. The electricity price is varied from 20 to $60 \mathrm{EUR} / \mathrm{MWh}$, with current values at around 40 EUR/MWh in Sweden. The biomass price will depend on the quality and moisture content of the biomass resource, which in this study is varied from 0 to $40 \mathrm{EUR} / \mathrm{MWh}$, on an as-received basis for a moisture content of $40 \%$. High-quality woody biomass fuel corresponds to wood pellets, with prices at around 25 EUR/MWh. A large-scale plant would, however, most likely be fueled with forest residues, with prices at around $20 \mathrm{EUR} / \mathrm{MWh}$, or with recovered wood, the price of which varies in the range 0-10 EUR/MWh [35].

As the DFB-DR route has the potential to create significant negative $\mathrm{CO}_{2}$ emissions, the total production cost of the LS can be modified to account for the revenue of the sequestered $\mathrm{CO}_{2}$, if society places a value on removing $\mathrm{CO}_{2}$ from the atmosphere. In this work, the revenue considered for the negative $\mathrm{CO}_{2}$ ranges from $0 \mathrm{EUR} / \mathrm{t} \mathrm{CO}_{2}$ to $100 \mathrm{EUR} / \mathrm{t} \mathrm{CO}$. In contrast, the BF-BOF and NG-DR routes rely on fossil fuels and emit large amounts of $\mathrm{CO}_{2}$. In addition to revenue from negative emissions, the total production cost of the various routes can be compared while accounting for the penalty cost linked to emitting fossil $\mathrm{CO}_{2}$, with a carbon price that can be set as equal to the revenue from negative emissions.

The total production costs of LS for the three DR routes are then calculated using Equation (11):

Production Cost $(\mathrm{EUR} / \mathrm{t} \mathrm{LS})=Y_{\text {red gas }} \cdot C_{\text {red gas }}+C_{D R I+E A F}+c_{e l} \cdot Y_{E A F}-c_{n e g} C O_{2} \cdot Y_{n e g} C O_{2}$

The first term in Equation (11) is the cost associated with the reducing gas, where $Y_{\text {red gas }}$ is the reducing gas consumption in MWh/t LS and $C_{\text {red gas }}$ is the cost of the reducing gas in EUR/MWh. The second term, $C_{D R I+E A F}$, is the total cost, in EUR/ $\mathrm{tS}$, of the DR reactor and EAF, accounting for the annualized CAPEX and OPEX, as determined in Sections 4.4.1 and 4.4.2, respectively. The third term is the electricity consumption of the EAF, based on an energy consumption $Y_{E A F}$ of $450 \mathrm{kWh} / \mathrm{t} \mathrm{LS}$, as given in Section 4.1.5, and based on the variable electricity price $c_{e l}$. The fourth term is the revenue associated with negative emissions, where $c_{n e g} \mathrm{CO}_{2}$ is the revenue in $\mathrm{EUR} / \mathrm{t} \mathrm{CO}$ and $Y_{n e g} \mathrm{CO}_{2}$ is the production rate of negative emissions in $\mathrm{t} / \mathrm{t}$ LS.

\section{5. $\mathrm{CO}_{2}$ Emissions Reduction Relative to the BF-BOF Route}

The three DR routes compared in this work all confer significant reductions in emissions compared with the $\mathrm{BF}-\mathrm{BOF}$ route. The $\mathrm{CO}_{2}$ emissions for the $\mathrm{BF}-\mathrm{BOF}$ route are assumed to be $1900 \mathrm{kgCO}_{2} / \mathrm{t}$ LS, based on a range of $1600-2200 \mathrm{~kg} / \mathrm{t}$ steel [53]. The emissions for the NG-DR route are set at $1150 \mathrm{kgCO}_{2} / \mathrm{t} \mathrm{LS} \mathrm{[2].} \mathrm{Note} \mathrm{that} \mathrm{these} \mathrm{two} \mathrm{routes} \mathrm{can}$ be modified to reduce their emissions levels, even without using a biogenic or renewable 
reduction agent, for instance via $\mathrm{CO}_{2}$ capture. However, the present work focuses on comparisons of the well-established instances of these technologies.

For the $\mathrm{H}_{2}$-DR route, assuming that the electricity used is generated fossil-free and that biochar is used in the EAF, the only positive $\mathrm{CO}_{2}$ emissions are related to the flux agent used in the EAF and the graphite electrodes. Assuming that this flux agent is pure limestone $\left(\mathrm{CaCO}_{3}\right)$, the $\mathrm{H}_{2}$-DR route has positive emissions of $25 \mathrm{kgCO}_{2} / \mathrm{t} \mathrm{LS}$. Based on a consumption of $2 \mathrm{~kg}$ of graphite electrodes per tonne of steel, the associated emissions amount to $7 \mathrm{kgCO}_{2} / \mathrm{t} \mathrm{LS}$. On this basis, the only positive emissions from the DFB-DR also originate from limestone and graphite electrode consumption and are set at the same value of $32 \mathrm{kgCO}_{2} / \mathrm{t}$ LS. All other emissions from the DFB-DR route, here again assuming a fossil-free electricity source, are either neutral or negative, given the biogenic origin of the fuel used. It is also assumed, for the sake of comparibility, that the pelletization plant that provides iron ore pellets to all three DR routes can be operated without positive emissions.

\section{Results}

\subsection{Compositions of the Gases to and from the DR Reactor}

Table 6 shows the volumetric concentration, $\mathrm{H}_{2} / \mathrm{CO}$ ratio, and $\mathrm{RP}$ of the cold gas, i.e., the gas from the DFB gasifier after the removal of tar and BTX and $\mathrm{CO}_{2}$ separation, the reducing gas, the carburizing gas, and the top-gas. The requirements imposed on the RP for the reducing gas and the top-gas are met, with RP values above 8.7 and 1.7, respectively. This indicates that the reducing gas will have the reducing power needed to reduce the iron ore to $\mathrm{Fe}$ and that re-oxidation will be limited. Similarly, the carburization gas has a high $\mathrm{RP}$, which indicates that the level of oxidation of $\mathrm{Fe}$ to $\mathrm{FeO}$ in the bottom region of the furnace will be limited.

Table 6. Compositions of the cold-gas, reducing gas, carburization gas, and top-gas in the DFB-DR route. Species concentrations are given in volume percent. $\mathrm{RP}$ refers to the reduction potential, which is defined as $\left(\mathrm{H}_{2}+\mathrm{CO}\right) /\left(\mathrm{H}_{2} \mathrm{O}+\mathrm{CO}_{2}\right)$.

\begin{tabular}{cccccccccccc}
\hline & $\mathbf{H}_{\mathbf{2}}$ & $\mathbf{C O}$ & $\mathbf{C O}_{\mathbf{2}}$ & $\mathbf{H}_{\mathbf{2}} \mathbf{O}$ & $\mathbf{C H}_{\mathbf{4}}$ & $\mathbf{C}_{\mathbf{2}} \mathbf{H}_{\mathbf{4}}$ & $\mathbf{C}_{\mathbf{2}} \mathbf{H}_{\mathbf{2}}$ & $\mathbf{C}_{\mathbf{2}} \mathbf{H}_{\mathbf{6}}$ & $\mathbf{C}_{\mathbf{3}} \mathrm{H}_{\mathbf{6}}$ & $\mathbf{H}_{\mathbf{2}} / \mathbf{C O}$ & $\mathbf{R P}$ \\
\hline Cold-gas $^{\mathbf{a}}$ & 61.4 & 28.0 & 1.4 & 0.0 & 6.7 & 1.8 & 0.0 & 0.4 & 0.3 & 2.2 & 62.9 \\
Reducing gas $^{\mathbf{b}}$ & 74.8 & 18.6 & 0.8 & 5.6 & 0.0 & 0.0 & 0.0 & 0.0 & 0.0 & 4.0 & 14.4 \\
Carburizing gas $^{c}$ & 65.8 & 17.6 & 4.5 & 6.0 & 4.2 & 1.4 & 0.0 & 0.3 & 0.3 & 3.8 & 8.0 \\
Top-gas $^{c}$ & 61.0 & 11.0 & 8.4 & 19.6 & 0.0 & 0.0 & 0.0 & 0.0 & 0.0 & 5.6 & 2.6 \\
\hline
\end{tabular}

${ }^{\mathrm{a}}$ After $\mathrm{CO}_{2}$ separation. ${ }^{\mathrm{b}}$ After mixing with recirculated top-gas and $\mathrm{H}_{2}$ from electrolysis, and a temperature rise to $1000{ }^{\circ} \mathrm{C} .{ }^{\mathrm{c}}$ Includes the recycled carburization gas.

The $\mathrm{H}_{2} / \mathrm{CO}$ ratio of the reducing gas from the DFB-DR route is much higher than the typical value for the NG-DR route (see Table 1). This higher $\mathrm{H}_{2} / \mathrm{CO}$ ratio is due to two factors: (1) natural gas is reformed partly with $\mathrm{CO}_{2}$ in addition to $\mathrm{H}_{2} \mathrm{O}$ in the NG-DR route, thereby decreasing the ratio, and (2) in the proposed process, hydrogen from electrolysis is added. This higher $\mathrm{H}_{2} / \mathrm{CO}$ ratio partly explains the higher $\mathrm{RP}$ of the top-gas obtained in the DFB-DR route (as compared to the NG-DR route), as a higher $\mathrm{H}_{2} / \mathrm{CO}$ ratio implies an overall more endothermic reduction reaction, such that the heat balance of the DR reactor will constrain the amount of iron ore reduced.

The carburization gas is rich in $\mathrm{H}_{2}$ and $\mathrm{CO}$, as compared with its content of hydrocarbons. As a consequence, from the gas availability perspective, carburization will predominantly occur via R2 and R3. However, this does not account for the kinetics of the carburization reactions. Carburization with $\mathrm{H}_{2}$ and $\mathrm{CO}$ is beneficial in terms of extracting a higher-temperature DRI to reduce energy consumption in the EAF, given that the reactions are exothermic, whereas the reaction with methane is endothermic.

\subsection{Operating Parameters}

In addition to the parameters that are fixed based on the assumptions described in Section 4.1, some operating parameters are determined from the mass and energy balances, as well as other requirements. Table 7 describes these parameters. The oxygen transport 
from the combustor to the bed reducer is $27 \%$ of the stoichiometric oxygen demand for combustion of the total fuel input to the DFB loop. This corresponds to the amount of oxygen that needs to be taken up by the slag bed material to produce the heat necessary for the heat balance of the DFB loop to be closed. The fraction of cold gas sent to carburization is the split of the cold gas between the carburizing and reducing gas. This value is fixed by the set requirement for a $\%$ wt carbon content of the DRI. The recirculation of the top-gas to the reducing gas is set so that there is just enough $\mathrm{H}_{2}$ and $\mathrm{CO}$ in the gas sent to the bed reducer such that the oxygen transport from the bed reducer to the gasifier is limited to $5 \%$. Finally, the excess gas in the DR reactor represents the fraction of the reducing $\mathrm{H}_{2}$ and $\mathrm{CO}$ that actually reacts with the iron ore. This parameter is defined by the heat balance of the $\mathrm{DR}$ reactor and fixes the $\mathrm{RP}$ of the top-gas.

Table 7. Operating parameters of the DFB-DR routeThese are the parameters that are not fixed based on assumptions but determined so that the mass and energy balances are respected.

\begin{tabular}{ccc}
\hline Operating Parameter & Unit & Value \\
\hline Oxygen transport Combustor-Bed reducer & \% of stoichiometric $\mathrm{O}_{2}$ for & 27 \\
Fraction of cold gas to carburization & combustion of fuel & 26 \\
Top-gas recirculation & $\%$ & 83 \\
Excess gas in the DR & $\%$ & 23 \\
\hline
\end{tabular}

\subsection{Performance of the DR Routes}

The raw gas and cold gas efficiencies of the DFB gasification loop are $83 \%$ and $76 \%$, respectively. These can be compared with the raw gas and cold gas efficiencies of $87.3 \%$ and $71.7 \%$, respectively, determined for the GoBiGas plant by Alamia et al. [39]. The gasification section efficiency is $79 \%$. The overall DRI production efficiencies of the compared DR processes are shown in Figure 4. The NG-DR route has the highest efficiency because: (1) it has the lowest $\mathrm{H}_{2} / \mathrm{CO}$ ratio in the reducing gas, which leads to a less endothermic reduction in the DR reactor; (2) the heat for the reformer is provided by combustion with air, thereby avoiding the energy penalty associated with producing pure $\mathrm{O}_{2}$; and (3) the reducing gas exiting the reformer is at a temperature of around $950{ }^{\circ} \mathrm{C}$, which means that only a low level of natural gas combustion is needed to reach the desired temperature. Conversely, the $\mathrm{H}_{2}$-DR route has the lowest efficiency, mainly because its reducing gas does not contain $\mathrm{CO}$, so the reduction reaction is the most endothermic of the three routes. Furthermore, a significant efficiency penalty is incurred by the need to burn $10 \%$ of the reducing gas with pure $\mathrm{O}_{2}$, as the reducing gas preheating is limited by the temperature $\left(350{ }^{\circ} \mathrm{C}\right)$ of the top-gas. The DFB-DR route has an efficiency that is only one percentage point higher than that of the $\mathrm{H}_{2}$-DR route. However, when calculated on a wet biomass basis, which is the state in which the biomass is introduced into the DFB-DR process, the efficiency reaches $57 \%$. When one accounts for the fact that part of the energy input is used to produce a pure $\mathrm{CO}_{2}$ stream, $\varepsilon_{D F B, 3}$, the efficiency becomes equivalent to that of the NG-DR route, at $73 \%$.

\subsection{Carbon Distribution and $\mathrm{CO}_{2}$ Emission Reductions}

The distribution of carbon in the various outputs of the DFB-DR process is shown in Table 8, as a fraction of the total carbon input and as a production rate relative to the production of LS. The total carbon input includes the biomass, the scrubbing agent for tar removal, the carbon in the limestone $\left(\mathrm{CaCO}_{3}\right)$ used as flux in the EAF, and the graphite electrodes. The carbon of the last two inputs is released to the atmosphere as $\mathrm{CO}_{2}$. Note, however, that it does not include the carbon in the MEA scrubbing agent used for $\mathrm{CO}_{2}$ separation. Most of the carbon introduced into the system is sequestered, and this leads entirely to negative emissions, provided that the tar scrubbing agent is of biogenic origin. This results in negative emissions of $880 \mathrm{kt} /$ year for a $1 \mathrm{Mt} /$ year plant operating for $8000 \mathrm{~h}$ at full load. The extracted char and BTX together account for almost one-quarter of the 
carbon input. The production rate of BTX is relatively low but these molecules have a high intrinsic value, so their associated revenue could be high relative to their low production rate. $\mathrm{CO}_{2}$ emissions amount to $160 \mathrm{~kg} / \mathrm{t}$ LS but are mostly neutral given the biogenic origin of the carbon and under the assumption that the forest or crop from which they originate is properly managed. Only $32 \mathrm{~kg}$ of the $\mathrm{CO}_{2}$ emissions are not of biogenic origin, as they come from the limestone and graphite inputs, as mentioned in Section 4.5.

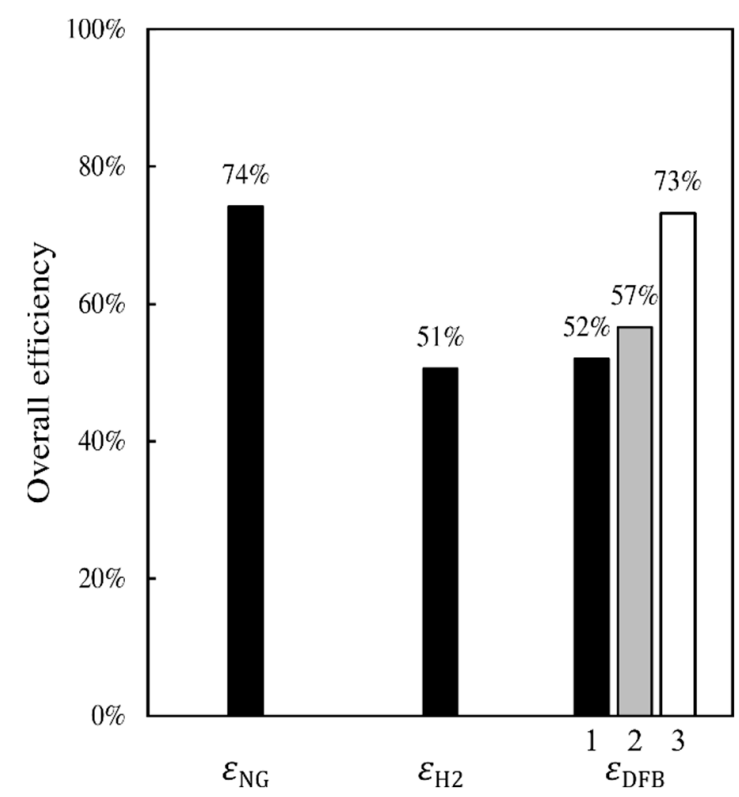

Figure 4. Overall DRI production efficiencies for the NG-DR, $\mathrm{H}_{2}-\mathrm{DR}$, and DFB-DR routes. The efficiencies are defined in Table 3. Columns 1, 2, and 3 for the efficiency of the DFB refer to $\varepsilon_{D F B, 1}$, $\varepsilon_{D F B, 2}$, and $\varepsilon_{D F B, 3}$, respectively.

Table 8. Distribution of carbon in the outputs of the process, in terms of the fraction of the total carbon input, which accounts for the carbon in the biomass, the scrubbing agent (RME in the calculations), and the $\mathrm{CO}_{2}$ from the flux agent, which is assumed to be $\mathrm{CaCO}_{3}$ in the calculations. The production yields of the outputs are also shown in $\mathrm{kg} / \mathrm{t}$ liquid steel.

\begin{tabular}{ccc}
\hline Carbon Output & Carbon Content (\% of Input) & Production (kg/t LS) \\
\hline Emitted $\mathrm{CO}_{2}$ & 11.6 & 159 \\
Sequestered $\mathrm{CO}_{2}$ & 64.4 & 879 \\
Char & 21.7 & 90 \\
$\mathrm{BTX}$ & 1.7 & 7 \\
Carbon in steel & 0.6 & 2 \\
\hline
\end{tabular}

The high rate of $\mathrm{CO}_{2}$ sequestration from the plant results in net-negative emissions of $850 \mathrm{~kg} \mathrm{CO}_{2} / \mathrm{t}$ LS. Compared with the emissions of a typical BF-BOF plant, this corresponds to a net decrease in emissions of $2750 \mathrm{~kg} / \mathrm{t} \mathrm{LS}$ or a relative decrease of $145 \%$. This is compared in Figure 5 to the decrease in emissions relative to a BF-BOF plant for the NG-DR and $\mathrm{H}_{2}$-DR routes.

\subsection{Economics}

The CAPEX and OPEX (excluding biomass and electricity prices) of the DFB-DR route are described in Table 9. The dimensions of the main units are also given. For a plant that produces $1 \mathrm{Mt}$ /year of steel, a $460 \mathrm{MW}$ DFB gasification plant is needed, as well as a $115 \mathrm{MW}$ electrolysis plant. The CAPEX values are given as a range, corresponding to the lower and higher investment cost estimates for the DFB and the gas-handling sections, as described in Section 4.4.1. The total investment cost of the DFB-DR route is between 
760 MEUR and almost 1000 MEUR. In comparison, the CAPEX for the NG-DR route is $570 \mathrm{EUR} / \mathrm{t}$ capacity of steel, that for the $\mathrm{H}_{2}-\mathrm{DR}$ route is $700 \mathrm{EUR} / \mathrm{t}$ capacity of steel. The investment cost of the proposed DFB-DR route is, therefore, $7-40 \%$ higher than that of the $\mathrm{H}_{2}$-DR route and $30-75 \%$ higher than that of the NG-DR route. This difference in investment cost is attributed to the cost of the DFB gasification unit and attached gashandling section, which account for $39-55 \%$ of the CAPEX, and to the fact that the DFB-DR route also has an electrolyzer, which accounts for $8-11 \%$ of the investment. The OPEX of the DFB-DR route amounts to about $280 \mathrm{EUR} / \mathrm{t} \mathrm{LS}$ and is dominated by the price of the iron pellets, which is $170 \mathrm{EUR} / \mathrm{t} \mathrm{LS}$.

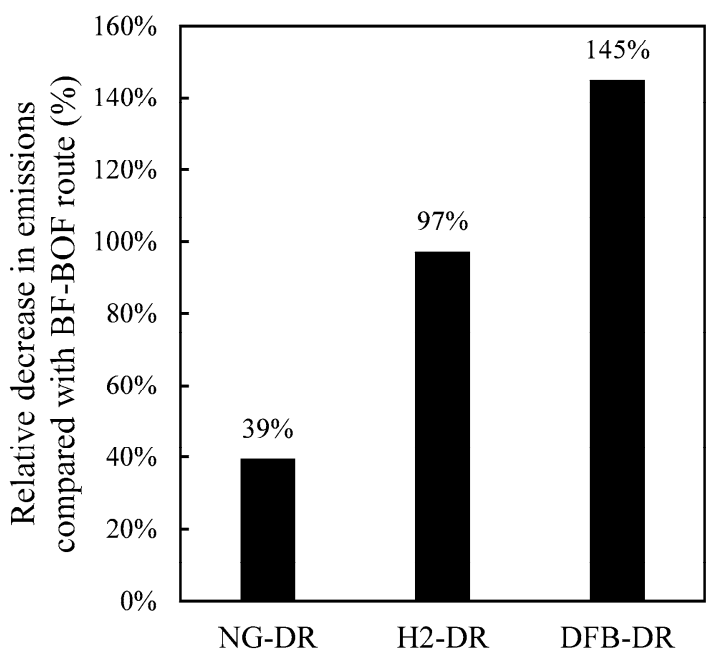

Figure 5. Decrease in $\mathrm{CO}_{2}$ emissions relative to the $\mathrm{BF}-\mathrm{BOF}$ route for the DFB-DR route, compared with the NG-DR and $\mathrm{H}_{2}$-DR routes.

Table 9. CAPEX and OPEX for the DFB unit and gas-handling section, the DRI-EAF section, and the electrolysis section, for a plant that produces $1 \mathrm{Mt}$ steel per year. The OPEX does not include the costs for biomass and electricity, nor does it account for revenues associated with negative $\mathrm{CO}_{2}$ emissions. However, it accounts for the cost of the iron pellets.

\begin{tabular}{|c|c|c|c|c|}
\hline Title & DFB and Gas-Handling Section & DRI-EAF & Electrolyzer & Total \\
\hline Unit Dimension & $460 \mathrm{MW}$ (DFB) & $1 \mathrm{Mt} /$ Year & $115 \mathrm{MW}$ & \\
\hline CAPEX (MEUR) & $290-550$ & 370 & 80 & $760-1000$ \\
\hline Annualized CAPEX (EUR/t LS) & $23-44$ & 30 & 6 & $59-80$ \\
\hline OPEX $^{\mathrm{a}}(\mathrm{EUR} / \mathrm{t}$ LS) & 24 & 250 & 3 & 277 \\
\hline Fraction of total CAPEX (\%) & $39-55$ & $50-37$ & $11-8$ & 100 \\
\hline Fraction of total OPEX a $(\%)$ & 9 & 90 & 1 & 100 \\
\hline
\end{tabular}

${ }^{\text {a }}$ Excluding the costs of biomass and electricity.

Figure 6 shows the reducing gas costs for the three routes, as a function of the electricity price. For the DFB-DR route, the lower and upper boundaries are given, based on a biomass price of 0 EUR/MWh and the lower CAPEX for the DFB for the lower boundary, as well as a biomass price of $40 \mathrm{EUR} / \mathrm{MWh}$ and the higher DFB CAPEX for the upper boundary. A median case is also presented. The $\mathrm{H}_{2}$-DR case has the highest reducing gas cost compared with the DFB-DR low and median cases and the NG-DR case. When the electricity price is $>40$ EUR/MWh, the reducing gas cost of the $\mathrm{H}_{2}$-DR case also exceeds the upper boundary of the estimated cost of the DFB-DR route. Conversely, the NG-DR route yields the lowest cost, which is even lower than the lower boundary of the estimate for the DFB-DR case. This can be explained by the high-level efficiency of the NG-DR route, wherein the consumption of natural gas is low and the heating demand of the reformer can be easily covered by burning a fraction of the top-gas. 


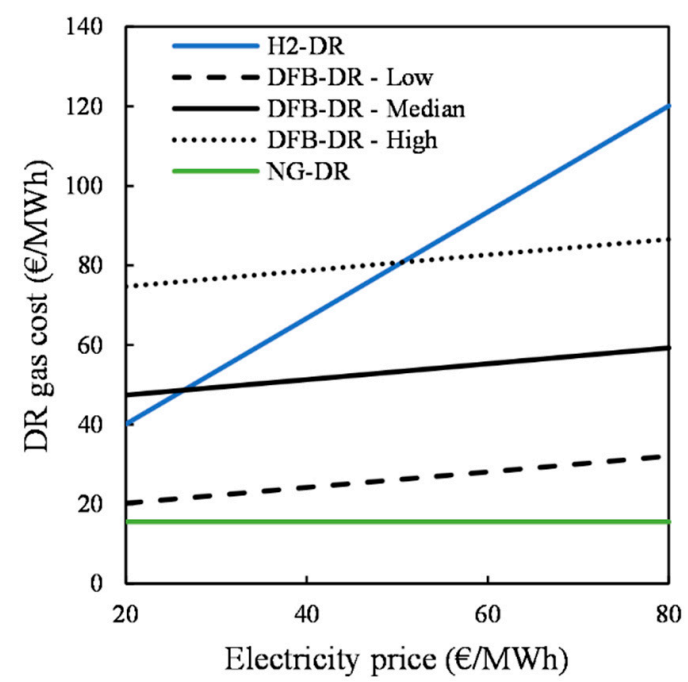

Figure 6. Costs for the reducing gas sent to the DR reactor for the three DR routes. For the DFB-DR route, the "Low" series is based on a biomass price of 0 EUR/MWh and the lower boundary of the CAPEX of the DFB loop and the gas-handling section, whereas the "High" series is based on a biomass price of $40 \mathrm{EUR} / \mathrm{MWh}$ and the upper boundary of the CAPEX.

Figure 7a shows the total production cost of LS for the three DR routes and a re-lined BF-BOF steel mill (see Sections 4.4.1 and 4.4.2), for an electricity price of $40 \mathrm{EUR} / \mathrm{MWh}$ and revenues accrued from negative $\mathrm{CO}_{2}$ emissions that range from $0 \mathrm{EUR} / \mathrm{t} \mathrm{CO}_{2}$ to $100 \mathrm{EUR} / \mathrm{t} \mathrm{CO}$. Figure $7 \mathrm{~b}$ shows the cut-off electricity price, above which the DFB-DR route becomes more competitive than the $\mathrm{H}_{2}$-DR route, shown for several negative $\mathrm{CO}_{2}$ emissions revenues. The DFB-DR case is based on the "Median" cost estimation for the CAPEX of the DFB unit and the gas-handling section.

As shown in Figure 7a, for an electricity price of $40 \mathrm{EUR} / \mathrm{MWh}$, in the absence of any revenue from negative $\mathrm{CO}_{2}$ emissions, the DFB-DR route is not competitive with the NG-DR and BF-BOF routes. With the added revenue from negative $\mathrm{CO}_{2}$ emissions, the DFB-DR route can compete with the NG-DR route only when recovered wood is used as the biomass and for negative emissions revenues $>60 \mathrm{EUR} / \mathrm{t} \mathrm{CO}$. Competition with the BF-BOF route is only possible when this revenue exceeds $100 \mathrm{EUR} / \mathrm{t} \mathrm{CO}$ and only when very low-quality recovered wood is used. Lower electricity prices (not shown in the figure) slightly improve the competitiveness of the DFB-DR route in relation to the two fossil-based routes, although revenue from negative $\mathrm{CO}_{2}$ emissions remains necessary and the biomass used must be recovered wood. Figure $7 \mathrm{~b}$ shows that without revenue from negative emissions, the DFB-DR route is competitive compared with the $\mathrm{H}_{2}$-DR route for electricity prices $>35 \mathrm{EUR} / \mathrm{MWh}$ when forest residues are used as biomass (20 EUR/MWh), as well as at any electricity price $>20 \mathrm{EUR} / \mathrm{MWh}$ when recovered wood is used. When negative emissions revenues are introduced, the DFB-DR route rapidly becomes more competitive, aside from cases with very high biomass prices and low electricity prices. Note that the values shown in Figure 7 do not account for either revenues received from the extracted char and BTX for the DFB-DR route or revenue collected from selling pure oxygen in the $\mathrm{H}_{2}$-DR route.

However, Figure 7a does not account for the fact that significant costs can be associated with the high levels of emissions from the NG-DR and BF-BOF routes. Assuming that the price paid for $\mathrm{CO}_{2}$ emissions is the same as the revenue obtained from negative emissions, then the production costs of the NG-DR and BF-BOF routes are greatly increased, as shown in Figure 8, for electricity and biomass prices of 40 EUR/MWh and 20 EUR/MWh, respectively. At a carbon price above $60 \mathrm{EUR} / \mathrm{t} \mathrm{CO}$, the DFB-DR route becomes the most competitive, albeit again without accounting for the added revenues from char and BTX. 
Electricity: $40 € / \mathrm{MWh}$

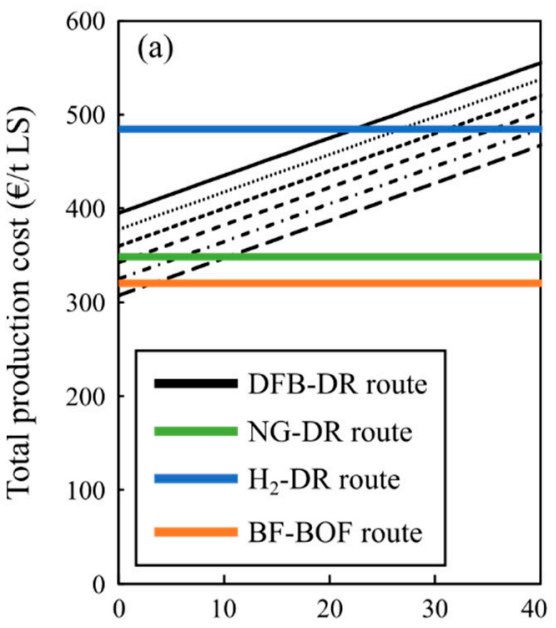

Biomass price ( $€ / \mathrm{MWh}$ as received)

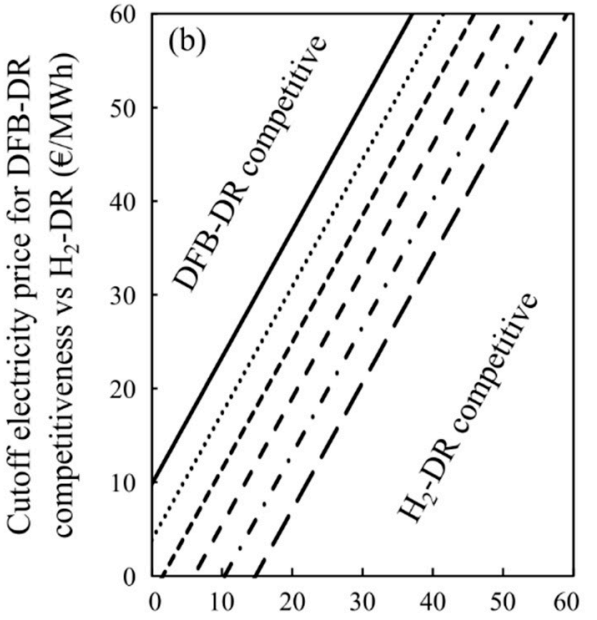

Biomass price (€/MWh as received)

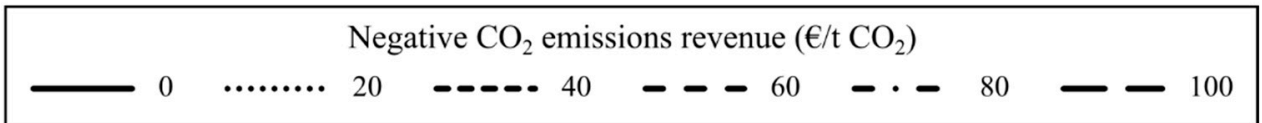

Figure 7. Total production cost of the various routes, and cutoff electricity price for which the DFB-DR route is competitive compared with the $\mathrm{H}_{2}$-DR route. (a) Total production costs (in EUR/t liquid steel) for the three DR routes and the traditional BF-BOF route (value from Vogl et al. [47]), as a function of the biomass price (in EUR/MWh) and the revenue associated with negative $\mathrm{CO}_{2}$ emissions (EUR/t $\mathrm{CO}_{2}$ ), for an electricity price of $40 \mathrm{EUR} / \mathrm{MWh}$. The various lines for the DFB-DR route correspond to the revenues accrued from negative $\mathrm{CO}_{2}$ emissions, ranging from $0 \mathrm{EUR} / \mathrm{t}$ (top line) to $100 \mathrm{EUR} / \mathrm{t}$ (bottom line), with the dashed lines indicating increments of $20 \mathrm{EUR} / \mathrm{t}$. The DFB-DR case is based on the "Median" cost estimation for the CAPEX of the DFB unit and the gas-handling section. (b) Cutoff electricity price, above which the DFB-DR route is more competitive economically than the $\mathrm{H}_{2}-\mathrm{DR}$ route, for various revenues from negative $\mathrm{CO}_{2}$ emissions. The biomass price is on an as-received basis for a moisture content of $40 \%$.

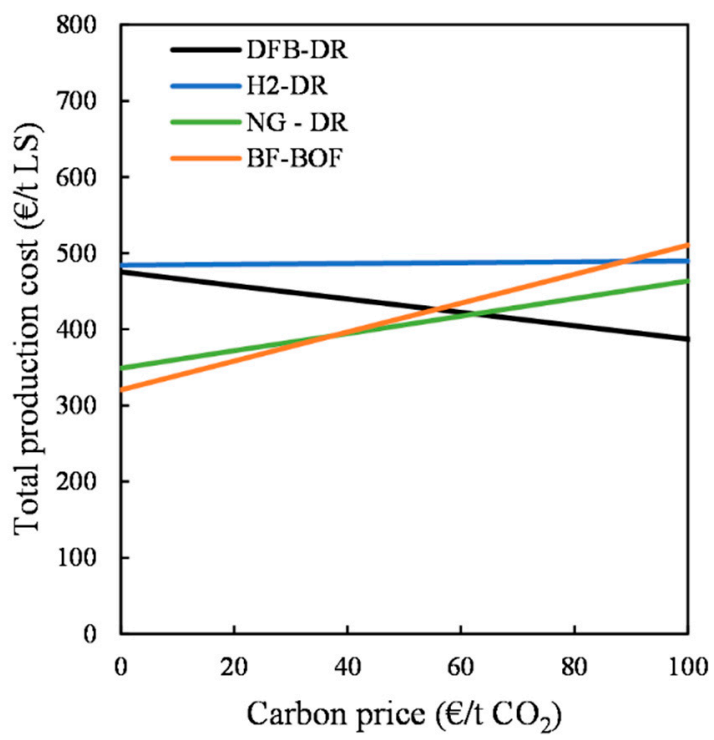

Figure 8. Total production costs of the three DR routes and the BF-BOF route, as a function of the carbon price, assuming that the revenues accrued from negative carbon emissions are equal (in EUR/t $\mathrm{CO}_{2}$ ) to the price for emitting $\mathrm{CO}_{2}$. The assumed prices for biomass and electricity are $20 \mathrm{EUR} / \mathrm{MWh}$ and $40 \mathrm{EUR} / \mathrm{MWh}$, respectively. 


\section{Discussion}

The results presented in this work reveal that the DFB gasification loop and gashandling section proposed for the DFB-DR route can provide a reducing gas of quality similar to that of a natural-gas-based MIDREX plant, and whose reduction potential is, therefore, sufficient to achieve a high degree of metallization in the DR reactor. The DFB gasification loop shows an energetic efficiency that is comparable to those of typical DFB gasification systems, such as the GoBiGas plant. Comparing the efficiencies of the three DR routes, the NG-DR route appears to have the highest efficiency and the $\mathrm{H}_{2}$-DR route has the lowest efficiency. The efficiency of the DFB-DR route is only slightly higher than that of the $\mathrm{H}_{2}$-DR route, when determined on a dry biomass basis. However, when calculating this efficiency on a wet biomass basis and accounting for the fact that part of the heat produced from the process is used to create pure $\mathrm{CO}_{2}$ for sequestration, then the efficiency of the DFB-DR route becomes similar to that of the NG-DR route (see Figure 4). Figure 5 highlights one of the main appeals of the DFB-DR route compared with the other two DR routes: not only does it result in significant reductions in emissions relative to the $\mathrm{BF}-\mathrm{BOF}$ route, but it also leads to negative emissions, thereby attaching to its produced steel the image of a product that is not just "clean" in itself but actually contributes to "cleaning" the atmosphere.

However, the possibility to produce negative $\mathrm{CO}_{2}$ emissions, as well as valuable byproducts such as biochar and BTX, comes at a cost. Indeed, the economic analysis shows investment costs for the DFB-DR route that are much higher than those for the NG-DR, $\mathrm{H}_{2}$-DR, and greenfield BF-BOF routes. This high investment cost, combined with the costs for biomass and electricity, results in an overall high production cost, which means that the DFB-DR route can only be competitive with the other routes if substantial value is assigned to negative emissions. Nonetheless, if $\mathrm{CO}_{2}$ emissions are penalized to the same extent that negative emissions are rewarded, then the DFB-DR route becomes the most competitive for carbon prices $>60 \mathrm{EUR} / \mathrm{t} \mathrm{CO}_{2}$. On the other hand, as stated by Wörtler et al., a full feasibility analysis must account for Europe's overcapacity with respect to the $\mathrm{BF}-\mathrm{BOF}$ route, meaning that a technologic switch to the DRI-EAF routes would require massive investment in decommissioning existing BF-BOF plants [43]. Nonetheless, this is not expected to significantly change the general conclusion drawn from Figure 8 , and it is likely that carbon prices $<100 \mathrm{EUR} / \mathrm{t} \mathrm{CO}_{2}$ will be sufficient to make the DFB-DR route the most competitive route for steelmaking.

According to the results shown in Figure 8, the $\mathrm{H}_{2}$-DR route never becomes the most economically viable route at current electricity prices. Even if electricity prices decrease, the $\mathrm{H}_{2}$-DR route cannot compete with the DFB-DR route when revenue from negative emissions is introduced, as shown in Figure $7 \mathrm{~b}$. However, biomass availability, or lack thereof, is likely to limit the potential of the DFB-DR route, such that a combination of the two routes, as well as other low-carbon steelmaking technologies, is likely to constitute the best solution in the future. Note that the $\mathrm{H}_{2}$-DR route as assessed by Vogl et al. has a lower level of $\mathrm{H}_{2}$ consumption than the $\mathrm{H}_{2}$-DR route assessed in the present work, $51 \mathrm{vs} .84 \mathrm{~kg}$ $\mathrm{H}_{2} / \mathrm{t} \mathrm{LS}$, and thereby a lower reducing gas cost and lower production cost of the liquid steel [47]. This difference arises from the estimation of the energy consumption of the DR reactor and the possibility for heat recovery from the top-gas. Additionally, in the study of Vogl et al. [47], the heating demand after heat recovery is provided by electricity. In the present work, the operation of the DR reactor was set to be the same as that for the NG-DR and DFB-DR routes. This might, however, not be the optimal way to operate the DR when using pure hydrogen. Furthermore, the main efficiency loss is related to the combustion of $\mathrm{H}_{2}$ so as to reach the desired temperature in the DR reactor. This loss could be reduced by using high-temperature electrolysis. Not accounted for in this work is the fact that, as mentioned in Section 2.3, the $\mathrm{H}_{2}-\mathrm{DR}$ route does not provide carburization of the DRI that it produces, which leads to different behaviors in and requirements for the EAF.

The results of this work are consistent with those reported by Hammerschmid et al. for the production of a reducing gas for DR via SER and OxySER [11]. Those authors estimated 
a reducing gas cost in the range of 10-15 EUR/GJ, equivalent to 36-54 EUR/MWh, which is comparable to the range of 45-60 EUR/MWh estimated for the "Median" DFB-DR case in Figure 6. The estimated $\mathrm{CO}_{2}$ production for carbon capture and utilization (CCU) for a 100-MW OxySER plant is $36,100 \mathrm{~kg} / \mathrm{h}$, corresponding to around $360 \mathrm{~kg} \mathrm{CO} 2 / \mathrm{MWh}$ reducing gas, which is comparable to the $880 \mathrm{~kg} \mathrm{CO}_{2} / \mathrm{t} \mathrm{LS}$ produced for sequestration in the proposed process, which is equivalent to $320 \mathrm{~kg} \mathrm{CO}_{2} / \mathrm{MWh}$ reducing gas. The results of the present work are also similar to those of Hammerschmid et al. [11] when it comes to the economic viability of the DFB process. In both works, the DFB design that produces significant amounts of $\mathrm{CO}_{2}$ for sequestration or utilization (OxySER for Hammerschmid et al.) only becomes competitive with the natural gas reforming route if value can be derived from the $\mathrm{CO}_{2}$ via its sequestration or utilization. Apart from the difference in DFB gasification configuration, another major difference between the processes is that the DFB-DR route described herein proposes the use of an electrolysis plant, whereas the OxySER route proposed by Hammerschmid and coworkers is based on the use of an ASU. Hammerschmid and colleagues state that the possibility to use the existing ASU of a DRI-EAF plant is important with respect to the economic viability of the proposed route. Our work, in combination with that of Hammerschmid et al. [11], further supports the viability of producing steel with potentially negative emissions using DFB gasification and highlights the flexibility of this technology, as it can be operated in various configurations to serve a similar purpose.

The DFB-DR concept presented in this work takes advantage of the flexibility of the DFB gasification technology. The possibility to use an iron-rich, oxygen-carrying bed material allows for low levels of $\mathrm{CO}_{2}$ emissions in the flue gas as well as for the possibility to source this bed from steelmaking slag, which is a byproduct, thereby enhancing the circularity of the proposed process. The presence of a combustor that is separated from the gasifier offers the possibility to easily deal with waste streams. For instance, handling the gas from the EAF has generally been a challenge, due to the presence of $\mathrm{CO}$ and $\mathrm{N}_{2}$ and the high dust content. In the proposed process, this gas can be treated in the combustor, where $\mathrm{CO}$ is burnt, and the dust is removed in the existing flue gas dust removal step. The presence of the bed reducer in the DFB loop allows simultaneous treatment of the non-recycled top-gas from the DR reactor so as to reduce the bed and limit the undesirable transport of oxygen to the gasifier, as well as to produce a $\mathrm{CO}_{2}$-rich stream that only needs conditioning in order to be transported and sequestered.

The process proposed in this work also represents a good case for the use of a chemicallooping technology, in particular the chemical-looping gasification (CLG) technology to which the DFB loop in this work is analogous. A major challenge with CLG is the oxidation of the raw gas by the oxygen transported from the combustor (referred to as the 'air reactor' in the chemical-looping literature). The bed reducer and the non-recirculated top-gas offer an interesting solution to this challenge in that they can limit the transport of oxygen to the gasifier and produce a reduced bed material with high catalytic potential. A consequence of the lower level of oxidation of the raw gas by the bed is that higher levels of $\mathrm{H}_{2}$ and $\mathrm{CO}$ are available for the reducing gas and that the energy demand for $\mathrm{CO}_{2}$ separation is decreased. In CLG, complete gasification of the biomass is generally the goal to avoid carbon slippage to the air reactor. The transport of oxygen facilitates high gasification rates by removing inhibitors [54], and reactor temperatures $>850{ }^{\circ} \mathrm{C}$ are typical. In the proposed process, it is also desirable to avoid char slippage to the combustor, as this represents a loss of negative emissions and thereby a potential loss of revenue. Given the larger amount of char transported out of the gasifier compared with a typical CLG, a higher-efficiency carbon stripper is required.

The choice of operating temperature for the gasifier will emerge from an economic optimization exercise. Higher temperatures will increase the $\mathrm{H}_{2}$ and $\mathrm{CO}$ yields in the reducing gas due to enhanced gasification and reforming reactions, which should entail a higher yield of reduced iron. The enhanced gasification reaction will also result in lower char flows to the carbon stripper, thereby reducing both the risk of slippage to the 
combustor and the risk of loss of negative emissions. However, this reduces the yield of char and the level of associated revenue. Additionally, the higher heat demand of the DFB loop resulting from the higher temperature means that greater uptake of oxygen by the bed is needed. This, in turn, means that more top-gas needs to be diverted to the bed reducer instead of being recirculated to the DR reactor to maintain a low level of oxygen transport to the gasifier. Overall, the gasifier temperature and the degree of recirculation of the top-gas should be optimized by considering the yield and value of all the outputs. Additives can also be used in the DFB loop to increase catalytic activity and contribute to the optimization. The flexibility of the DFB gasification technology ensures that several paths can be considered for this optimization, while accounting for factors other than the production cost and revenues.

Potential issues related to the agglomeration of the ash and the bed will also motivate the choice of operating temperature. Agglomeration tendencies with woody biomass, the fuel proposed in this work, are rather limited but will be significant if biomass rich in silica and alkali is used as the fuel. BOF-slag has been used in a $12-\mathrm{MW}_{\text {th }}$ circulating fluidized bed boiler with woody biomass for two weeks at temperatures ranging $840-870{ }^{\circ} \mathrm{C}$ and mixed with silica sand, without any agglomeration issues reported [25]. This suggests that bed agglomeration issues at the temperatures proposed in this work will be limited. To avoid agglomeration, the accumulation of ash components in the bed can be limited through frequent replacement of the bed material with virgin slag, whose low cost makes this option viable. Controlling the temperature in the DFB loop is another way to limit agglomeration. This can be achieved by increasing the sensible heat demands in the gasifier and combustor by reducing the degree of preheating of inlet gases to the DFB system or by recirculating part of the combustor's flue gas to its inlet.

The efficiency of the DR step would be increased if a reducing gas with a lower $\mathrm{H}_{2} / \mathrm{CO}$ ratio could be produced. The $\mathrm{H}_{2} / \mathrm{CO}$ ratio can be lowered if an ASU is used to produce pure $\mathrm{O}_{2}$ instead of an electrolyzer. However, this decreases the yield of reducing gas and, thereby, the yield of DRI relative to the biomass consumption. The operation of the DFB loop can also be adjusted to lower the $\mathrm{H}_{2} / \mathrm{CO}$ ratio. Using a less catalytically active bed material is one option. However, the reduced slag bed material contains large fractions of iron and calcium species, both of which are known to catalyze the reforming reactions and the WGS, leading to an increased $\mathrm{H}_{2} / \mathrm{CO}$ ratio. Diluting the bed with an inert material could be a way to decrease the activity of the bed and, thereby, reduce the proportion of $\mathrm{H}_{2}$. However, this may affect the heat balance, as the oxygen-carrying iron fraction is removed. If, once they are in bed material form, the iron-rich and calcium-rich fractions of the slag are sufficiently differentiated, then the bed could be enriched for iron relative to calcium via magnetic separation, taking advantage of the ferromagnetic property of the iron-rich fraction. This would allow enrichment of the bed with oxygen-carrying particles. Ultimately, a more in-depth study is needed to establish whether a lower $\mathrm{H}_{2} / \mathrm{CO}$ ratio is desirable from the efficiency and economic perspectives and to establish ways to achieve this lower $\mathrm{H}_{2} / \mathrm{CO}$ ratio.

\section{Conclusions}

A DFB gasification process for the production of reducing gas for the direct reduction of iron is proposed and compared with the traditional, natural-gas-based DR route, NG-DR, and the emerging electrolysis-based route, $\mathrm{H}_{2}-\mathrm{DR}$. The DFB-DR process is found to be capable of producing a reducing gas that meets the requirement of the MIDREX process, which is the most commonly used DR reactor type. Compared with the other two routes, the DFB-DR route also produces biochar and BTX, which are valuable byproducts. More importantly, it is the only one of the three routes that can generate negative $\mathrm{CO}_{2}$ emissions, promoting a decrease in emissions of $145 \%$ compared with the BF-BOF route. The energy efficiency of the DFB-DR route is comparable to the NG-DR route at close to $75 \%$, when determined on a wet biomass basis and accounting for the fact that char, $\mathrm{BTX}$, and $\mathrm{CO}_{2}$ are valuable byproducts in the efficiency definition. 
The level of complexity of the DFB gasification loop and associated gas-handling section that produces the reducing gas, as compared with those of the reformer of the NG-DR route and electrolyzer of the $\mathrm{H}_{2}$-DR route, leads to investment costs that are much higher than those of the other routes. Nevertheless, the cost of producing the reducing gas for the DFB-DR route, which is in the range of 45-60 EUR/MWh for the median cost estimate, is lower than that for the $\mathrm{H}_{2}$-DR route, although it is higher than for the NG-DR route. Based on the cost of the reducing gas, the total production costs for the liquid steel are determined and compared for the three DR routes, as well as for the BF-BOF route. In the absence of any revenue from negative $\mathrm{CO}_{2}$ emissions, the DFB-DR route is competitive only with the $\mathrm{H}_{2}$-DR route. When it includes this revenue stream, the DFB-DR route can be competitive with the fossil-fuel-based routes, although it can only really compete with the $\mathrm{BF}-\mathrm{BOF}$ route when cheap recovered wood is used, electricity prices are low, and negative $\mathrm{CO}_{2}$ emissions revenues are $>100 \mathrm{EUR} / \mathrm{t} \mathrm{CO}$. However, when accounting for the cost associated with $\mathrm{CO}_{2}$ emissions and setting its value equal to the revenue for negative $\mathrm{CO}_{2}$ emissions, the DFB-DR route becomes the most competitive route at a carbon price $>60 \mathrm{EUR} / \mathrm{t} \mathrm{CO}_{2}$. Under the assumptions made in this work, the $\mathrm{H}_{2}$-DR route never becomes economically viable, although these results are mainly applicable to the situation in Sweden. A thorough analysis would need to account for biomass availability and local variability in prices.

The case presented in this work is an example of the flexibility of the DFB gasification technology in providing a range of carbon-neutral or carbon-negative services. The process presented in this work makes use of the slag from BOF and EAF, which is a waste product from steelmaking processes, to separate $\mathrm{CO}_{2}$ from nitrogen. The DFB gasification process could, however, be operated in other configurations. Alternatively, the proposed process could be operated under different conditions of temperature and catalytic activity. Nevertheless, this work shows the technical and economic feasibilities of DFB gasification for producing reducing gas in direct ironmaking and showcases the strong potential for the implementation of DFB gasification in industries other than those concerned with heat and power production and petrochemical processes.

Author Contributions: Conceptualization, S.P., H.T. and P.S.; methodology, S.P., H.T. and P.S.; investigation, S.P.; data curation, S.P.; writing—original draft preparation, S.P.; writing-review and editing, H.T., P.S. and M.S.; visualization, S.P.; supervision, H.T. and M.S.; funding acquisition, H.T. and P.S. All authors have read and agreed to the published version of the manuscript.

Funding: This research was a part of the FerroSilva project, co-funded by the Swedish Energy Agency under grant 51220-1.

Institutional Review Board Statement: Not applicable.

Informed Consent Statement: Not applicable.

Data Availability Statement: The data presented in this study is contained within the article and the references it cites.

Conflicts of Interest: The authors declare no conflict of interest.

\section{References}

1. European Commission. SETIS-Energy Efficiency in the Iron and Steel Industry. Available online: https://setis.ec.europa. eu/technologies/energy-intensive-industries/energy-efficiency-and-co2-reduction-iron-steel-industry/info (accessed on 23 February 2021).

2. Direct From MIDREX-1st Quarter 2020. 2020. Available online: www.midrex.com (accessed on 30 June 2021).

3. HYBRIT-Summary of Findings from HYBRIT Pre-Feasibility Study 2016-2017. Available online: https://ssabwebsitecdn. azureedge.net/-/media/hybrit/files / hybrit_brochure.pdf?m=20180201085027 (accessed on 30 June 2021).

4. Masson-Delmotte, V.; Zhai, P.; Pörtner, H.-O.; Roberts, D.; Skea, J.; Shukla, P.R.; Pirani, A.; Moufouma-Okia, W.; Péan, C.; Pidcock, R.; et al. Global Warming of $1.5^{\circ} \mathrm{C}$ an IPCC Special Report; IPCC: Geneva, Switzerland, 2018; ISBN 9789291691517. Available online: https: / / www.ipcc.ch/sr15/ (accessed on 30 June 2021).

5. Fuss, S.; Canadell, J.G.; Peters, G.P.; Tavoni, M.; Andrew, R.M.; Ciais, P.; Jackson, R.B.; Jones, C.D.; Kraxner, F.; Nakicenovic, N.; et al. Betting on negative emissions. Nat. Clim. Chang. 2014, 4, 850-853. [CrossRef] 
6. Larsson, A.; Kuba, M.; Berdugo Vilches, T.; Seemann, M.; Hofbauer, H.; Thunman, H. Steam gasification of biomass-Typical gas quality and operational strategies derived from industrial-scale plants. Fuel Process. Technol. 2021, 212, 106609. [CrossRef]

7. Larsson, A.; Seemann, M.; Neves, D.; Thunman, H. Evaluation of Performance of Industrial-Scale Dual Fluidized Bed Gasifiers Using the Chalmers 2-4-MWth Gasifier. Energy Fuels 2013, 27, 6665-6680. [CrossRef]

8. Rosenfeld, D.C.; Hans, B.; Lindorfer, J.; Lehner, M. Scenario analysis of implementing a power-to-gas and biomass gasi fi cation system in an integrated steel plant: A techno-economic and environmental study. Renew. Energy 2020, 147, 1511-1524. [CrossRef]

9. Müller, S.; Theiss, L.; Fleiß, B.; Hammerschmid, M.; Fuchs, J.; Penthor, S.; Rosenfeld, D.C.; Lehner, M.; Hofbauer, H. Dual fluidized bed based technologies for carbon dioxide reduction-Example hot metal production. Biomass Convers. Biorefinery 2021, 11, 159-168. [CrossRef]

10. Fuchs, J.; Schmid, J.C.; Müller, S.; Hofbauer, H. Dual fluidized bed gasification of biomass with selective carbon dioxide removal and limestone as bed material: A review. Renew. Sustain. Energy Rev. 2019, 107, 212-231. [CrossRef]

11. Hammerschmid, M.; Müller, S.; Fuchs, J.; Hofbauer, H. Evaluation of biomass-based production of below zero emission reducing gas for the iron and steel industry. Biomass Convers. Biorefinery 2021, 11, 169-187. [CrossRef]

12. Thunman, H.; Seemann, M.; Berdugo Vilches, T.; Maric, J.; Pallares, D.; Ström, H.; Berndes, G.; Knutsson, P.; Larsson, A.; Breitholtz, C.; et al. Advanced biofuel production via gasification-Lessons learned from 200 man-years of research activity with Chalmers' research gasifier and the GoBiGas demonstration plant. Energy Sci. Eng. 2018, 6, 6-34. [CrossRef]

13. Direct from MIDREX-Third Quarter 2017. 2017. Available online: www.midrex.com (accessed on 30 June 2021).

14. Tanaka, H. Potential for CO2 Emissions Reduction in MIDREX Direct Reduction Process. 2013. Available online: https://ieaghg. org/docs/General_Docs/Iron\%20and\%20Steel\%202\%20Secured\%20presentations/2_1400\%20Hidetoshi\%20Tanaka.pdf (accessed on 30 June 2021).

15. Morales, J. Economics with High-Carbon DRI from ENERGIRON DR Technology. In Proceedings of the 19th Middle East Iron \& Steel Conference, Dubai, United Arab Emirates, 14-17 December 2015.

16. Kirschen, M.; Badr, K.; Pfeifer, H. Influence of direct reduced iron on the energy balance of the electric arc furnace in steel industry. Energy 2011, 36, 6146-6155. [CrossRef]

17. Lule, R.; Lopez, F.; Espinoza, J.; Torres, R.; Morales, R.D. The Production of steels applying $100 \%$ DRI for nitrogen removal. In Proceedings of the AISTech-Iron and Steel Technology Conference Proceedings, St. Louis, MI, USA, 4-7 May 2009.

18. Rentz, O.; Spengler, T. Report on Best Available Techniques (BAT) in the Electric Steelmaking Industry; Umweltbundesamt: Karlsruhe, Germany, 1997.

19. Brand, A.S.; Fanijo, E.O. A review of the influence of steel furnace slag type on the properties of cementitious composites. Appl. Sci. 2020, 10, 8210. [CrossRef]

20. Pissot, S.; Berdugo Vilches, T.; Thunman, H.; Seemann, M. Dual Fluidized Bed Gasification Configurations for Carbon Recovery from Biomass. Energy Fuels 2020, 34, 16187-16200. [CrossRef]

21. Fan, L.-S.; Zeng, L.; Wang, W.; Luo, S. Chemical looping processes for $\mathrm{CO}_{2}$ capture and carbonaceous fuel conversion-Prospect and opportunity. Energy Environ. Sci. 2012, 5, 7254-7280. [CrossRef]

22. Adánez, J.; Abad, A.; Mendiara, T.; Gayán, P.; De Diego, L.F.; García-Labiano, F. Chemical looping combustion of solid fuels. Prog. Energy Combust. Sci. 2018, 65, 6-66. [CrossRef]

23. Lyngfelt, A.; Brink, A.; Langørgen, Ø.; Mattisson, T.; Rydén, M.; Linderholm, C. 11,000 h of chemical-looping combustion operation-Where are we and where do we want to go? Int. J. Greenh. Gas Control 2019, 88, 38-56. [CrossRef]

24. Lind, F.; Corcoran, A.; Thunman, H. Validation of the oxygen buffering ability of bed materials used for OCAC in a large scale CFB boiler. Powder Technol. 2017, 316, 462-468. [CrossRef]

25. Rydén, M.; Hanning, M.; Lind, F. Oxygen Carrier Aided Combustion (OCAC) of Wood Chips in a 12 MWth Circulating Fluidized Bed Boiler Using Steel Converter Slag as Bed Material. Appl. Sci. 2018, 8, 2657. [CrossRef]

26. Hildor, F.; Mattisson, T.; Leion, H.; Linderholm, C.; Rydén, M. Steel converter slag as an oxygen carrier in a 12 MWth CFB boiler-Ash interaction and material evolution. Int. J. Greenh. Gas Control 2019, 88, 321-331. [CrossRef]

27. Hildor, F.; Leion, H.; Linderholm, C.J.; Mattisson, T. Steel converter slag as an oxygen carrier for chemical-looping gasification. Fuel Process. Technol. 2020, 210, 106576. [CrossRef]

28. Kramp, M.; Thon, A.; Hartge, E.U.; Heinrich, S.; Werther, J. Carbon Stripping-A Critical Process Step in Chemical Looping Combustion of Solid Fuels. Chem. Eng. Technol. 2012, 35, 497-507. [CrossRef]

29. Iaquaniello, G.; Antonetti, E.; Cucchiella, B.; Palo, E.; Salladini, A.; Guarinoni, A.; Lainati, A.; Basini, L. Natural Gas Catalytic Partial Oxidation: A Way to Syngas and Bulk Chemicals Production. In Natural Gas Extraction to End Use; Gupta, S., Ed.; IntechOpen: London, UK, 2012; ISBN 978-953-51-0820-7.

30. Direct from MIDREX-3rd Quarter 2019. 2019. Available online: www.midrex.com (accessed on 30 June 2021).

31. Béchara, R.; Hamadeh, H.; Mirgaux, O.; Patisson, F. Optimization of the Iron Ore Direct Reduction Process through Multiscale Process Modeling. Materials 2018, 11, 1094. [CrossRef] [PubMed]

32. Parisi, D.R.; Laborde, M.A. Modeling of counter current moving bed gas-solid reactor used in direct reduction of iron ore. Chem. Eng. J. 2004, 104, 35-43. [CrossRef]

33. Milne, T.A.; Evans, R.J.; Abatzoglou, N. Biomass Gasifier "Tars": Their Nature, Formation, and Conversion; National Renewable Energy Laboratory: Golden, CO, USA, 1998. Available online: https:/ / www.osti.gov/servlets/purl/3726 (accessed on 30 June 2021). 
34. Maggiolo, D.; Seemann, M.; Thunman, H.; Santos, O.; Larsson, A.; Sasic, S.; Ström, H. Self-Cleaning Surfaces for Heat Recovery During Industrial Hydrocarbon-Rich Gas Cooling: An Experimental and Numerical Study. AIChE J. 2019, 65, 317-325. [CrossRef]

35. Thunman, H.; Gustavsson, C.; Larsson, A.; Gunnarsson, I.; Tengberg, F. Economic assessment of advanced biofuel production via gasification using cost data from the GoBiGas plant. Energy Sci. Eng. 2019, 7, 217-229. [CrossRef]

36. Bui, M.; Adjiman, C.S.; Bardow, A.; Anthony, E.J.; Boston, A.; Brown, S.; Fennell, P.S.; Fuss, S.; Galindo, A.; Hackett, L.A.; et al. Carbon capture and storage (CCS): The way forward. Energy Environ. Sci. 2018, 11, 1062-1176. [CrossRef]

37. Alamia, A.; Thunman, H.; Seemann, M. Process Simulation of Dual Fluidized Bed Gasifiers Using Experimental Data. Energy Fuels 2016, 30, 4017-4033. [CrossRef]

38. Brynolf, S.; Taljegard, M.; Grahn, M.; Hansson, J. Electrofuels for the transport sector: A review of production costs. Renew. Sustain. Energy Rev. 2018, 81, 1887-1905. [CrossRef]

39. Alamia, A.; Larsson, A.; Breitholtz, C.; Thunman, H. Performance of large-scale biomass gasifiers in a biorefinery, a state-of-the-art reference. Int. J. Energy Res. 2017, 41, 2001-2019. [CrossRef]

40. Peters, M.S.; Timmerhaus, K.D.; West, R.E. Chapter 6: Analysis of Cost Estimation. In Plant Design and Economics for Chemical Engineers; McGraw-Hill Education: New York, NY, USA, 2002.

41. Lockwood Greene Technologies Ironmaking Process Alternative Screening Study, Volume II: Appendix. 2000. Available online: https: / / digital.library.unt.edu/ark:/67531/metadc892419/ (accessed on 30 June 2021).

42. IEA. The Future of Hydrogen-Seizing Today's Opportunities. 2019. Available online: https://www.iea.org/reports/the-future-ofhydrogen (accessed on 30 June 2021).

43. Wörtler, M.; Schuler, F.; Voigt, N.; Schmidt, T.; Dahlmann, P.; Bodo Lüngen, H.; Ghenda, J.-T. Steel's Contribution to a LowCarbon Europe 2050 Technical and Economic Analysis of the Sector's CO2 Abatement Potential. 2013. Available online: https:/ / www.bcg.com/publications/2013/metals-mining-environment-steels-contribution-low-carbon-europe-2050 (accessed on 7 August 2021).

44. Pardo, N.; Moya, J.A. Prospective scenarios on energy efficiency and $\mathrm{CO}_{2}$ emissions in the European Iron \& Steel industry. Energy 2013, 54, 113-128. [CrossRef]

45. Fischedick, M.; Marzinkowski, J.; Winzer, P.; Weigel, M. Techno-economic evaluation of innovative steel production technologies. J. Clean. Prod. 2014, 84, 563-580. [CrossRef]

46. Cavaliere, P. Chapter 8 Direct Reduced Iron: Most Efficient Technologies for Greenhouse Emissions Abatement. In Clean Ironmaking and Steelmaking Processes; Springer: Cham, Switzerland, 2019.

47. Vogl, V.; Åhman, M.; Nilsson, L.J. Assessment of hydrogen direct reduction for fossil-free steelmaking. J. Clean. Prod. 2018, 203, 736-745. [CrossRef]

48. Remus, R.; Aguado Monsonet, M.; Roudier, S.; Delgado Sancho, L. Best Available Techniques (BAT) Reference Document for Iron and Steel Production: Industrial Emissions Directive 2010/75/EU: (Integrated Pollution Prevention and Control); EUR 25521 EN; Publications Office of the European Union: Luxembourg, 2012; JRC69967.

49. ElexysNV Gas Spot Price TTF. Available online: https:/ / my.elexys.be/MarketInformation/SpotTtf.aspx (accessed on 9 June 2021).

50. Thunman, H.; Berdugo Vilches, T.; Seemann, M.; Maric, J.; Vela, I.C.; Pissot, S.; Nguyen, H.N.T. Circular use of plasticstransformation of existing petrochemical clusters into thermochemical recycling plants with $100 \%$ plastics recovery. Sustain. Mater. Technol. 2019, 22, e00124. [CrossRef]

51. IEA. Coal 2020; IEA: Paris, France, 2020; Available online: https:/ /www.iea.org/reports/coal-2020 (accessed on 30 June 2021)

52. Sveriges Geologiska Undersökning. METALLPRISER I JUNI 2021. Available online: https:/ / www.sgu.se/ (accessed on 30 June 2021).

53. Toktarova, A.; Karlsson, I.; Rootzén, J.; Göransson, L.; Odenberger, M.; Johnsson, F. Pathways for Low-Carbon Transition of the Steel Industry-A Swedish Case Study. Energies 2020, 13, 3840. [CrossRef]

54. Keller, M.; Leion, H.; Mattisson, T.; Lyngfelt, A. Gasification inhibition in chemical-looping combustion with solid fuels. Combust. Flame 2011, 158, 393-400. [CrossRef] 